\title{
GALILEO Y URBANO VIII. LA TRAMA DEL EQUÍVOCO
}

\author{
Antonio BELTRán Marf
}

El Decreto de 1616 que condenaba el copernicanismo era un tanto elusivo. Establecía más claramente lo que prohibía que lo que aún toleraba. Condenaba la teoría copernicana como teoría cosmológica y la pretensión de presentarla como verdadera, pero simplemente permitía deducir una imprecisa posibilidad de utilizarla hipotéticamente en el ámbito de la astronomía (Opere XIX, 322323) ${ }^{\prime}$. Dicho decreto prohibía el De revolutionibus de Copérnico "hasta que fuera corregido". El Decreto de corrección emanado de la Congregación del Indice, que finalmente se publicó en 1620 , enunciaba escuetamente lo que parecía implícito en el Decreto de 1616. Establecía que a pesar de la prohibición de 1616, "porque en ellos [los libros de la obra copernicana] hay muchas cosas muy útiles para la República" ${ }^{2}$, los cardenales de la Congregación del Indice habían deci-

' Cito por la edición de Favaro de Le Opere di Galileo Galilei, —véase en la bibliografía Galileo Galilei, Le Opere... que en adelante citaré como Opere, indicando el volumen en números romanos y la página en arábigos. En las otras referencias bibliográficas, que también pueden hallarse completas en la bibliografía del final, cito el autor seguido del año de la obra y el número de página correspondiente.

2 Se hace aquí referencia a la utilidad de la obra copernicana para las cuestiones relacionadas con el calendario. En su explicación de los criterios para la corrección, Francesco Ingoli — véase la nota siguiente- comentaba que la fijación del calendario y la determinación de las fechas de las festividades eclesiásticas requería de cálculos astronómicos que, a su vez, dependían de las observaciones acumuladas especialmente de las relativas al Sol, la Luna y la precesión de los equinoccios. A continuación añadía: "Y puesto que ciertamente los libros de Copérnico están llenos de tales observaciones, como es manifiesto a quien lo lee, dado que son útiles para la República, tienen que ser absolutamente conservados" (Bucciantini 1995, 207; Mayaud 1997, 71). Este punto era importante, puesto que en aquellos momentos se daba por sentado que la obra de Copérnico habla sido usada en la reforma gregoriana del calendario que se instituyó en 1582 . Así lo insinúa Ingoli en este mismo texto y, según afirmaría Urbano VIII años más tarde, (vease D'Addio 1993, 97, nota 94) esto fue un argumento decisivo para que en 1616 la teoría copernicana no fuera condenada absolutamente. 
dido"por acuerdo unánime" permitir la circulación de los ejemplares del De revolutionibus ya impresos y los que fueran a imprimirse, a condición de que se corrigieran los textos, que indicaba el Decreto, «en los que el lugar y el movimiento de la Tierra se discuten afirmativamente y no eex hypotesi»» (Bucciantini 1995, 211; Mayaud 1997, 70). Sólo las sesiones secretas de dicha Congregación en el proceso de discusión y preparación del Decreto de corrección, y más concretamente la propuesta presentada en 1618 por Francesco Ingoli ${ }^{3}$ para la corrección de la obra copernicana, nos proporcionan una clarificación de la posición asumida al respecto por las autoridades de la Iglesia. En su texto Ingoli especificaba inequívocamente que el "tratamiento hipotético" no incluía en ningún caso la consideración de la teoría copernicana como una hipótesis corroborable, sino que puntualizaba que, en el caso del libro de Copérnico como en la astronomía en general, se trataba del «uso de principios falsos para salvar las apariencias y los fenómenos celestes» (Mayaud 1997, 72). Este tipo de distinciones tenían una larga tradición epistemológica, pero en todo caso así se ratificaba la decisión "política" que había tomado el cardenal Bellarmino en 1615, cuando en la Carta a Foscarini había afirmado: «siempre he creído" que Copérnico había presentado su teoría "ex suppositione y no absolutamente" ${ }^{4}$ (Opere XII, 171). Nos consta

${ }^{3}$ Francesco Ingoli fue uno de los grandes protagonistas de la oposición oficial de la Iglesia al copernicanismo desde 1616. En los meses anteriores a la condena había escrito el opúsculo anticopernicano Disputatio de situ et quiete Terrae, en respuesta a la campaña procopernicana de Galileo. Por entonces estaba al servicio del cardenal Bonifacio Caetani, que fue encargado de la corrección del De Revolutionibus de Copérnico por la Congregación del Indice. Así lo afirma Galileo el 6 de marzo de 1616, es decir al día siguiente de la publicación del Decreto de condena (Opere XII, 244). No obstante, el cardenal Caetani murió en 1617, e Ingoli, apadrinado a partir de entonces por el cardenal Orazio Lancelotti, asumió la labor que le había sido encomendada a Caetani. Su propuesta de corrección de la obra copernicana fue apoyada por Christoph Grienberger y Orazio Grassi, matemáticos jesuitas del Colegio Romano que habían sido consultados, y aprobada por los cardenales de la Congregación del Indice, los cuales en principio decidieron que se publicara independientemente. Este texto de Ingoli, De enmendatione sex librorum Nicolai Copernici De Revolutionibus, ha sido publicado por Bucciantini, que ha estudiado con detalle la labor anticopernicana de Ingoli. Véase Bucciantini 1995, 207-209. Los documentos de la Congregación del Indice relativos a esta cuestión, incluido el mencionado texto de Ingoli, han sido publicados por Mayaud 1997.

${ }^{4}$ Opere XII, 171. A lo largo de 1615 Giovanni Ciampoli y Piero Dini sirvieron de intermediarios entre Galileo, en Florencia, y los cardenales Bellarmino y Maffeo Barberini, en Roma. Estos últimos fueron dejando claro que Galileo podría ocuparse del copernicanismo siempre que se mantuviera en el ámbito científico y matemático y dejara de lado su relación con las Escrituras, aunque en este segundo punto Bellarmino fue peligrosamente contradictorio. No obstante, tras la 
que Bellarmino no lo había creído siempre porque, según contaba Piero Dini, meses antes el cardenal había afirmado:

"que no puede creer que vaya a prohibirse, sino que lo peor que puede sucederle, según él, es que podría ponérsele alguna postilla, [en el sentido de] ${ }^{5}$ que su doctrina había sido presentada para salvar las apariencias o algo parecido, al modo de aquellos que han introducido los epiciclos y después no creen en ellos" ${ }^{6}$

Está claro que desde la Carta a Foscarini, Bellarmino había decidido creer y sobre todo imponer la creencia o la tesis de que Copérnico se presentó en el De revolutionibus como un ficcionalista. Y en 1618-1620 Ingoli racionalizaba esta decisión dándole cobertura retórico-epistemológica. Las "postillas" o correcciones de los textos puntuales de Copérnico podían «hacerse sin prejuicio para la verdad y las Escrituras» porque era el método propio de la astronomía (propriisima methodus) el utilizar principios falsos para salvar los fenómenos, por tanto, insistía Ingoli

"si los pasajes no hipotéticos de Copérnico sobre el movimiento de la Tierra se hacen hipotéticos, no serán contrarios ni a la verdad ni a las Escritura sagrada; por el contrario en cierto modo se corresponderán con ellas a causa de la naturaleza de la suposición falsa, de la que por un cierto derecho propio suele hacer uso la ciencia de la astronomía.» (Cit. en Mayaud 1997, 72).

Así pues, el falseamiento inicial y la eliminación posterior del realismo de Copérnico servían a la verdad teológica y eran legítimos en aras de la corrección metodológica.

denuncia de Galileo por parte de Tommaso Caccini ante la Inquisición, acusando el copernicanismo de herético, y de la publicación por parte del padre carmelita Paolo Antonio Foscarini de una Carta sobre la opinión de los pitagóricos y de Copérnico... en la que defendía la compatibilidad entre el copernicanismo y la Sagrada Escritura, Bellarmino radicalizó su posición y en su respuesta a Foscarini decidió, entre otras cosas, que tanto Copérnico como Galileo y Foscarini presentaban su copernicanismo como mera hipótesis y que obraban muy bien haciéndolo así.

5 Los textos entre corchetes que incluyo en las citas siempre son aclaraciones mías.

" (Opere XII, 151) Las "postillas" serían necesarias, obviamente, porque Copérnico presentaba su obra como realista, es decir afirmando la verdad de la teoría copernicana, como bien sabra Bellarmino. 
Naturalmente, tras la condena del copernicanismo, Galileo, que en 1615 había denunciado y tratado denodadamente de evitar aquella tergiversación de los hechos ${ }^{7}$, sólo podía asistir indignado y mudo a su consagración. Pero en 1621 murieron Bellarmino y Pablo V, protagonistas de la condena de 1616, y el nuevo Papa, Gregorio XV, aún siendo un gran protector de los jesuitas, que ahora protagonizaban la escena filosófica cultural católica, había aupado a algunos miembros de la Accademia dei Lincei ${ }^{8}$, como Giovanni Ciampoli y Virginio Cesarini, a cargos importantes de la corte papal. Acaso la nueva filosofía podría encontrar un nicho para sobrevivir. El hecho es que nos consta que a principios de 1623, antes de la publicación de Il Saggiatore, Galileo había retomado su Discurso sobre el flujo y el reflujo, que en 1616 había presentado como una prueba del movimiento terrestre, y estaba trabajando de nuevo en el tema, animado por Ciampoli y Cesarini (Opere XIII, 104 y 118-119). Cuando a finales de 1623 el cardenal Maffeo Barberini fue elegido como papa Urbano VIII, Galileo creyó en la posibilidad de la recuperación de la teoría copernicana y la revisión de su condena. A diferencia de Pablo V, Urbano VIII era un Papa refinado culturalmente, se consideraba un buen poeta y gustaba de relacionarse con los promotores de las nuevas ideas. Más aún, no sólo aceptó gustoso que Galileo le dedicara Il Saggiatore, que acababa de publicarse con el escudo de armas del Papa dibujado junto al de la Accademia dei Lincei, y apadrinó su presentación en una brillante

7 Ya en la Carta a Mons. Piero Dini de 23 de marzo de 1615, Galileo afirmaba: «De modo que, en mi opinión, la pretensión de que Copérnico no considerase verdadera la movilidad de la Tierra tan sólo podría hallar crédito acaso en quien no lo ha leídon (Opere V, 298). Poco después, en las Consideraciones sobre la opinión copernicana lo reiteraba en distintas ocasiones. En una de ellas, explicaba que uno de los errores básicos que se pretendían inculcar y él se proponía deshacer era que Copérnico había presentado su teoría como mera hipótesis matemática y no como una descripción verdadera de la disposición de los planetas en nuestro universo, y Galileo escribía al respecto: «los que persisten en afirmar esto ... muestran que han dado demasiado crédito a los informes de quien acaso habla más a su antojo que por el conocimiento del libro de Copérnico" (Ope$r e \mathrm{~V}, 353$ ). Más aún, en mayo de 1615 , denunciaba explícitamente el intento de hacerle pasar por un copernicano no realista y declaraba su temor de que eso pueda usarse para condenar la teoría como no verdadera (Opere XII, 185).

${ }^{8}$ La Accademia dei Lincei había sido fundada por el príncipe Federico Cesi, y aunque sus miembros tenían diferentes intereses e incluso filosofías distintas, aceptaban el liderazgo intelectual de Galileo. Un lema fundamental de la Academia era el respeto y defensa de la libertas philosophan$d i$, opuesto al principio de autoridad dominante. Así pues, respresentaban y se postulaban como una alternativa cultural y filosófica a la filosofía tradicional abanderada especialmente por los jesuitas y su Colegio Romano. 
ceremonia, sino que reía las pullas que Galileo hace en dicha obra contra el jesuita Orazio Grassi, matemático del Colegio Romano y gran representante del principio de autoridad y de la filosofía tradicional'. En abril de 1624 Galileo acudió esperanzado a Roma a explorar las posibilidades reales que la nueva coyuntura ofrecía a la recuperación del copernicanismo y a la revisión de su condena. Desde la primera de las seis audiencias que tuvo con el Papa, la desilusión de Galileo es evidente. A los pocos días de su llegada, inmediatamente después de hablar con el Papa durante más de una hora, escribe que le falta salud y esperanza para soportar las fatigas que requiere su gestión en la corte de Roma y comenta: "deseo volver a mi vida apacible y lo haré cuanto antes" (Opere XIII, 175). Cesi intenta animarle, el cardenal Zollern intenta mediar en su favor ante el Papa, pero los comentarios descorazonados por parte de Galileo se reiteran una y otra vez y su mensaje es claro: «Pero en conclusión, la cantidad de asuntos, considerados infinitamente más importantes que éstos, absorben y hacen inútil la aplicación a semejantes cuestiones» (Opere XIII, 179). El punto crucial es que la cuestión copernicana no es considerada importante y no interesa. Pero ante los comentarios del cardenal Zollern sobre la teoría copernicana y el uso que hacían de ella los protestantes para atacar a la Iglesia por su condena, el verboso Urbano VIII había comentado, según explicaba el cardenal,

"que la Santa Iglesia ${ }^{10}$ no la había condenado ni iba a condenarla como herética, sino como temeraria, pero que no había que temer que alguien jamás la fuera a demostrar como necesariamente verdaderan (Opere XIII, 182).

Respecto a la afirmación de que la Iglesia no había condenado la teoría copernicana como herética sino como temeraria, no se trata de si lo dicho por el Papa es verdadero o falso. La cuestión no es decidible en estos términos. En realidad Urbano VIII no estaba tanto haciendo una descripción de hechos históricos,

9 (Opere XIII, 145 y 146) Es muy dudoso que, incluso en estos momentos, Urbano VIII participara realmente de las nuevas ideas filosóficas desde una clara y meditada posición teórica, pero los innovadores no necesitaban desentrañar las auténticas creencias del nuevo Papa para intentar aprovechar la oportunidad.

10 Cabe notar que Urbano VIII dice "la Santa Iglesia». Ni se le ocurre hacer el distingo, que desde 1618 ya se había introducido y que después se considerará como crucial, entre "la Congregación del Indice» o «la Congregación de la Inquisición" y ula Santa Iglesia». Santillana cree destacable que la afirmación es uinexacta" (Santillana 1960, 320). En mi opinión, lo significativo y elocuente es que el Papa ni siquiera se plantee la distinción. 
como introduciendo una nueva interpretación del Decreto de condena de 1616. La decisión, tomada por razones políticas de auto justificación, de no incluir expresamente el término "herética» en el Decreto de 5 de marzo de 1616 podía ser aprovechada e incluso cargada retroactivamente de un sentido teológico diferente al que se le venía dando. Ahora Urbano VIII tenía la autoridad que le permitía reinterpretar la condena del copernicanismo, atribuyéndole una calificación teológica nueva. No se trata de refinamiento teológico, sino de poder. Lo afirmado ahora por el Papa ya había sido sugerido antes, por Foscarini y por Galileo por ejemplo, pero dicho por ellos o por cualquier católico de a pie podía ser causa de serios problemas con la Inquisición. El Papa en cambio tenía el poder de decidir que había margen de interpretación y, naturalmente, cuál era la interpretación correcta, y había hecho ambas cosas. La diferencia tácita que subyace a este cambio de calificación teológica es que si la teoría copernicana, contraria a las Escrituras, había sido condenada como «temeraria" y no como "herética", debía entenderse que la cuestión cosmológica debatida no era "materia de fe". Bellarmino había mantenido y expuesto la opinión contraria y, mientras vivió, la cosmología sí fue considerada materia de fe.

\section{El argumento de Urbano VIII}

Naturalmente la nueva interpretación de Urbano VIII no modificaba el silencio a que habían sido sometidos hasta entonces Galileo y los copernicanos controlables y, lo que es más importante, no estaba claro qué consecuencias prácticas implicaba para el futuro, porque había que tomar en cuenta la otra aseveración no menos crucial de Urbano VIII al cardenal Zollern: la indemostrabilidad de la teoría copernicana. Formalmente esta afirmación de Urbano VIII es prácticamente idéntica a la que había hecho el cardenal Bellarmino en su Carta a Foscarini. Tampoco el cardenal jesuita creía en la posibilidad de una demostración de la teoría copernicana (Opere XII, 172). Pero en el caso de Urbano VIII la base teórica de la afirmación no incluía explícitamente argumentos tomados del sentido común y la experiencia inmediata, sino que tenía una base teológica. Agostino Oreggi, teólogo personal de Urbano VIII, cuenta que éste, cuando todavía era cardenal ${ }^{11}$, había explicado a Galileo la futilidad de sus pretensiones al defen-

11 Eso significa que lo narrado debió acontecer en 1615-1616, pero es obvio que en 1624 Urbano VIII volvió a exponer o recordó su argumento, del que estaba muy orgulloso. En su obra De Deo uno tractatus primus, publicada en 1629, Agostino Oreggi contó cómo el Papa aleccionó a Galileo. 
der la verdad de la cosmología copernicana. La parte del texto de Oreggi que nos interesa aquí dice lo siguiente:

«Empecḱ a darme cuenta precisa de la importancia de este argumento cuando el sumo Pontífice Urbano VIII (al que Dios conserve sano para su Iglesia), todavía cardenal, aconsejó a un cliente suyo, no menos destacado por su ciencia que loable en la religión, que estudiara con detenimiento si concordaba con las Sagradas Escrituras lo que él había ideado acerca del movimiento de la Tierra para explicar todos los fenómenos que se ven en el cielo, y con cuanto aceptan los filósofos acerca de los movimientos del cielo y de los astros a partir de una observación detenida de los mismos y de su consideración global. Tras admitir todo lo que este hombre doctísimo había ideado, preguntó si Dios hubiera podido y sabido disponer de otro modo los orbes o las estrellas, de manera que cualesquiera fenómenos que se ven en el cielo, o los relativos al movimiento de los astros, a su orden, situación, distancia y disposición, pudieran ser salvados. Porque si dices que no, dijo el Santísimo, deberás probar que implica una contradicción que esto pueda suceder de un modo distinto a como lo has ideado. Pues con su poder infinito (infinita sua potentia), Dios puede todo cuanto no implica contradicción. Y puesto que la ciencia de Dios no es menor que su poder, si concedemos que Dios podría, debemos también afirmar que sabría. Si Dios podía y sabía disponer estas cosas de un modo diferente al que ha sido ideado, no debemos limitar el poder de Dios a este modo para salvar todas las cosas que se han mencionado. Oídas estas cosas, aquel hombre doctísimo se conformó (quievit). Y por ello recibió alabanzas de su conducta y de su ingenio ${ }^{12}$.

Lo primero que cabe notar es que antes de espetar su argumento decisivo, el entonces cardenal Barberini objetó como primera dificultad a Galileo la incompatibilidad de la teoría copernicana con las Escrituras y con la filosofía tradicional. Caben pocas dudas de que Maffeo Barberini compartía la postura de Bellarmino en estos puntos y que por sí mismos ya le parecían suficientemente contundentes contra el copernicanismo. Pero la concesión retórica en estas cues-

12 A. Oreggi, De Deo uno, 1629,193-195. Citado por Favaro 1992, vol. II, 615. Para la traducción del texto me he servido no sólo de la inestimable ayuda de Esther Artigas, sino también de la traducción italiana que dan Besomi y Helbing en su edición crítica del Diálogo (Besomi y Helbing 1998, II, 900-901), respecto a la que he introducido alguna pequeńa modificación. 
tiones aumentaba la importancia del argumento teológico, del que estaba tan orgulloso como si realmente lo hubiera inventado él. En realidad Galileo no quedó muy impresionado por el argumento en sí mismo, cuyo núcleo central conocía desde mucho antes. Simplemente, al cardenal Maffeo Barberini, que dogmatizaba con aquella seguridad y desparpajo, no podía contestarle lo que pensaba o creyó que en aquellos críticos momentos no era conveniente. Es decir, no se trataba de una discusión de tú a tú y parece que Galileo otorgó la conformidad de un oportuno silencio. En principio, con el cambio de situación y el cardenal Barberini ya papa Urbano VIII, Galileo se mostró más optimista, pero ya he mencionado su inmediata desilusión tras su primera conversación con el Papa. No conocemos el contenido concreto de sus conversaciones, pero nos consta que, en la medida en que pudo replicarle, Galileo no consiguió modificar la posición del Papa, sino que por el contrario tuvo que hacerla suya e incorporarla en sus proyectos, como veremos.

En realidad, el argumento tenía poco de original y había sido formulado de mil maneras y con distintos e incluso contrarios propósitos a lo largo de siglos ${ }^{13}$. Pero el tema de la omnipotencia de Dios adquirió una especial relevancia a partir de la condena que en 1277 promulgó el obispo de París, Étienne Tempier, de 219 proposiciones que se consideraban de raíz aristotélica; condena que reflejaba, entre otras cosas, las dificultades de asimilación de la filosofía aristotélica en la concepción cristiana. A través de ellas se reivindicaba la voluntad libre y la soberana libertad del Dios cristiano, frente al Dios de los filósofos que actúa con una voluntad inmutable ligada a la necesidad natural. Ateniéndonos al problema que nos interesa, el trasfondo del argumento de Urbano VIII es el siguiente. Si Dios puede hacer todo aquello que no implica contradicción, para saber por ejemplo cómo Dios decidió ordenar los cuerpos en el universo no bastará que presentemos argumentos correctos, demostraciones sólidas y pruebas experimentales de una determinada teoría; además tendremos que demostrar que todas las demás hipótesis posibles implican contradicción. Esto, evidentemente, no es factible entre otras cosas porque, en ese planteamiento, hay posibilidades que los humanos ni siquiera podemos imaginar y que Dios pudo realizar. Ni qué decir tiene que la misma conclusión o consecuencia es aplicable a toda teoría cosmo-

${ }^{13}$ Respecto a los orígenes del argumento puede verse Funkenstein 1986, esp. cap. 3; y Morpurgo-Tagliabue 1963, 94. Para una exposición crítica de los múltiples aspectos relacionados con esta cuestión y de su desarrollo histórico pueden verse los capítulos 2 y 3 de Bianchi 1990. 
lógica, incluyendo la aristotélico-ptolemaica. También en este caso habría que demostrar que todas las demás, incluida la copernicana, implican contradicción. Pero es obvio que a Urbano VIII esto no le preocupa ni, en la medida en que lo pensó, le interesa ponerlo de manifiesto. $Y$ desde luego no censuró, prohibió ni impuso cortapisa o condición alguna a ningún geocentrista y geostatista que afirmara la verdad de su teoría ${ }^{14}$. Urbano VIII no utiliza la fuerza del argumento, que también le obligaría a él al menos a equiparar todas las teorías cosmológicas, sino que utiliza su propia fuerza para dictaminar a qué y a quién afecta la compulsión lógico-teológica del argumento. De hecho es muy revelador el que en el siglo XIII la temática del poder absoluto de Dios hubiera sido utilizada contra puntos centrales de la cosmología aristotélica, que ahora Urbano VIII protegía invocando también la omnipotencia divina. Desde la premisa de que la única limitación del poder de Dios es lo lógicamente contradictorio, en numerosos artículos de 1277 se condenaba la idea de que Dios no puede hacer cosas naturalmente imposibles, como crear el vacío o varios mundos, o mover los cielos con movimiento rectilíneo. Así lo recordaba Campanella en 1616, en su Apologia pro Galileo $^{15}$. Bianchi, que ha destacado este punto ${ }^{16}$ y ha estudiado con detalle el tema de las condenas de 1277 y la temática de la omnipotencia divina, señala como un hecho básico la neutralidad teórica del argumento:

«La potencia absoluta de Dios desarrolló una función eminentemente 'retórica' además porque no era funcional, ni mucho menos constitutiva de una posición teórica concreta, porque no orientaba elecciones ni dictaba soluciones: era un instrumento de por sí neutro, potencialmente destructivo y potencialmente compatible con cualquier sistema conceptual. El hecho de que en el siglo XIII, con los destacables límites que acabamos de indicar, actuase prevalentemente contra el paradigma aristotélico, no debe hacernos olvidar que podía operar y operó a menudo a su favor.. ${ }^{17}$

${ }^{14}$ En el caso de Urbano VIII y su argumento ocurre algo similar a lo que sucede con Bellarmino y su supuesta "filosofía de la ciencia" ficcionalista o instrumentalista, que sólo aplicaba y exigía al copernicanismo pero no al geocentrismo.

is Campanella, (1616) 1994, 83-84.

16 Véase Bianchi 1999, 226-230.

17 Bianchi 1990, 131. Efectivamente, es bien sabido que a pesar de las condenas de París se fue imponiendo progresivamente un aristotelismo cristianizado que encarnaba la filosofía misma, y desde Juan XXI a Clemente VI pasó de estar prohibida a ser obligatoria en la misma universidad de París, como sus estatutos de 1366 establecían explícitamente. Véase al respecto Bianchi 
Las posibilidades del tema habían sido exploradas por los filósofos y teólogos, pero las autoridades eclesiásticas lo usaron, de modo eficazmente simplista, como un medio de control de la filosofía natural. Tanto el obispo Tempier en el siglo XIII, que fue inmediatamente apoyado por el papa Juan XXI, como Urbano VIII en el siglo XVII no tenían demasiado interés en los distintos aspectos de la cuestión teórica en sí; lo que les preocupaba era el control de las novedades y la protección del status quo sancionado por la Iglesia en sus respectivos momentos. Por eso mientras en el siglo XIII Tempier había utilizado el tema de la omnipotencia divina para conjurar los peligros del aristotelismo, en el siglo XVII Urbano VIII, tras la entronización del aristotelismo cristiano que se había radicalizado desde del Concilio de Trento, lo utilizaba como un instrumento represivo de la teoría copernicana y sólo de ella, que venía a competir con la aristotélico-ptolemaica. Como en el caso de Bellarmino en 1615, era el poder que se ejercía lo que daba fuerza y contundencia al argumento, no el argumento el que hacía fuerte a Urbano VIII.

En realidad lo que llama la atención del argumento de Urbano VIII, que dicho sea de paso no era teólogo, es que o bien equivalía a la negación de la distinción entre la potentia Dei absoluta y la ordinata, o al menos se concentraba exclusivamente en la omnipotencia absoluta, dictaminando la irrelevancia de la ordinata, o lo que es lo mismo la irrelevancia de la decisión de Dios de crear este mundo, tal y como es, y no otro. Esto iba en contra de las concepciones desarrolladas por los grandes teóricos del tema, como Tomas de Aquino u Occam,

1999, caps. 1 y 2. En el ámbito de la filosofía natural, a pesar de la crítica interna y la "libertad» que proporcionaba la premisa de la omnipotencia divina para pensar y desarrollar cualquier tesis claramente contraria a la filosofía de Aristóteles, la cosmología aristotélica cristianizada siguió siendo el marco de pensamiento que nutrió a los filósofos medievales cristianos. Incluso entre los medievalistas hoy se ha abandonado la idea de Duhem de que con la condena de 1277 nació la ciencia moderna y las tesis concomitantes, como por ejemplo que dadas las infinitas posibilidades de Dios para crear el mundo, el único modo de averiguar cómo lo creó realmente era la investigación empirica, básica para el nacimiento de la nueva ciencia. Así por ejemplo, E. Grant, que no es de los que más se ha distanciado del continuismo de Duhem, comenta: "Las 'imposibilidades naturales' que se exploraron como consecuencia de la condena [de 1277] representaron añadidos a la filosofía natural, pero no alteraron el núcleo de esta disciplina, no revolucionaron la filosofía natural aristotélica ni provocaron su abandono... [A pesar de todo lo dicho] Sería un serio error suponer que los teólogos se opusieron a la filosoffa natural aristotélica... Las ocasionales reacciones contra la filosofía natural [como las de 1210-1232 y las de 1277], cuando se ven contra el gran desarrollo de la historia de la cristiandad occidental, se convierten en aberraciones menores" (Grant 1996, 83 y 85 ). 
que si bien insistían en las infinitas posibilidades creativas de la potentia Dei absoluta, de ningún modo consideraban irrelevante el universo que Dios efectivamente creb, es decir nuestro universo, de potentia ordinata, porque según estos autores Dios se atenía escrupulosamente al orden creado por é ${ }^{18}$. Obviamente estamos ante el tipo de cuestiones que se caracterizan, en primer lugar, por el enorme potencial de arbitrariedad que encierran; en segundo lugar, porque no hay criterio alguno que permita determinar si una u otra tesis al respecto es verdadera o falsa, correcta o incorrecta. Por ello, para diferenciarlas es especialmente relevante tomar en cuenta el tipo de consecuencias que se derivan de una u otra y de su utilización. Ahora bien, resulta bastante claro que tanto en la postura tomista como en la occamista hay una preocupación por dar cabida al estudio de la naturaleza, a la filosofía natural en el marco del pensamiento y de la teología cristiana. En cambio resulta igualmente claro que la posición de Urbano VIII, en la medida en que lo hubiera reflexionado con un mínimo de atención, lo que no parece ser el caso, no muestra el más mínimo interés por que la paradójica noción de la omnipotencia divina sea compatible con alguna posibilidad de un conocimiento mínimamente fiable de la naturaleza, con una filosofía natural mínimamente sustantiva. La consecuencia última de la potentia Dei absoluta, tal como la entendía Urbano VIII, era la impenetrabilidad de la naturaleza, la imposibilidad de conocerla tal como es, es decir, la imposibilidad de conocer la opción concreta que Dios eligió al crear este universo en el que estamos. La idea de un cosmos, es decir, del universo como un todo organizado y regido por leyes naturales, venía a diluirse en las infinitas posibilidades de infinitos mundos posibles organizados y regidos de infinitos modos en la mente de un Dios libérrimo y sin limitación alguna en poder creador y de intervención en el mundo natural y humano. El Dios cristiano venía a constituirse así en garantía y condición de la imposibilidad de la ciencia. Todo esto equivalía a la más absoluta minusvaloración y desprecio de la razón y sus posibilidades. De este modo la razón humana y sus pretensiones científicas quedaban reducidas, a lo sumo, a mero entretenimiento cortesano de sobremesa, privado de toda trascendencia filosófica ${ }^{19}$, un rito cultural sometido al arbitraje del patrón.

${ }^{18}$ Para estos puntos véase Bianchi 1990, cap. II, esp. 81 y ss.; Funkenstein 1986, cap. III, B., esp. 124 y ss.

19 Eso casaba con las características y códigos de la cultura cortesana tal como las describe Biagioli. Biagioli 1993, 302 y ss. En las disputas cultas de sobremesa el gran mérito no era descubrir tesis verdaderas, sino ilustrar las infinitas posibilidades que la creación exhibe, los mil detalles inad- 
De hecho Galileo conocía los aspectos filosóficos de la problemática de la omnipotencia divina desde su época de escolar, como lo muestran sus comentarios al respecto en los Juvenilia $a^{20}$. Así pues, todo indica que en ya su periodo educativo Galileo no sólo se había aprendido la lección, quizás incluso de los mismos profesores jesuitas que se lo enseñaron a Urbano VIII, sino que además sabía que la noción de la omnipotencia divina se había usado contra elementos centrales de la cosmología aristotélica que ahora, en 1616 y en 1624, Urbano VIII intentaba proteger con esa misma noción. La dimensión política del argumento que delataba esa contradicción difícilmente podía inspirar mucho respeto a Galileo. Desde luego su silencio no se debía a que se hubiera quedado sin argumentos. Los tenía y en puntos centrales de sus ideas podía apelar a respetables antecedentes, como hemos visto. Pero si en principio el carácter indecidible de estas cuestiones podía permitirle reivindicar sus propuestas o por lo menos el derecho a discutirlas, era ese mismo carácter indecidible lo que, de hecho, hacía más incuestionable la autoridad del Papa y más inútil la discusión y el enfrentamiento dialéctico. Esa autoridad hacía que la opinión papal no fuera una más entre otras posibles, sino que se convirtiera en el criterio por el que habían de medirse todas las demás.

Tenemos razones para creer que, por propia iniciativa, Galileo no habría dedicado mucho tiempo al problema de Urbano VIII. En la medida en que lo considerara un problema genuino, no lo consideraba suyo ni estimaba en absoluto

vertidos que la observación atenta es capaz de sacar a la luz. En resumen, lo meritorio y admirable en el virtuoso no era, ni podía ser, el descubrimiento de la verdad, sino la ilustración de la riqueza inabarcable de la naturaleza. De ahí que Urbano VIII gozara especialmente con la fábula del sonido que inventa Galileo en Il Saggiatore, según la cual un hombre que cree que ha descubierto prácticamente todas las causas del sonido, intenta descubrir la causa de la estridulación que emite una cigarra y acaba matándola antes de conseguirlo. Para Urbano VIII se trataba sin duda de una ejemplificación paradigmática la prodigalidad inabarcable de la naturaleza en sus causas y efectos. En cierto modo también lo era para Galileo, pero éste estaba muy lejos de concluir de ello el escepticismo radical que postulaba Úrbano VIII y vio reflejado en la fábula.

${ }_{20}$ Por ejemplo, en estos textos escolares de juventud ya señalaba que la proposición a la que aludiría Campanella en su Apología, según la cual no puede existir más que una Tierra, era afirmada por Santo Tomás como de potentia naturali vel ordinaria, pero que también enseñaba que con su infinita potestas Dios podía crear varios mundos y varias tierras (Opere I, 29). En otro lugar alude a la potentia "que los teólogos llaman obediencial" (Opere I, 65), que remite no tanto a la dialéctica de las potentiae absoluta y ordinata, como a la de la voluntad absoluta y la voluntad determinada (conditionata). 
necesario darle una respuesta satisfactoria previa para llevar adelante su investigación científica. Su planteamiento no era ya el de los teólogos y filósofos naturales de los siglos XIII o XIV que, desde la absoluta prioridad de los dogmas cristianos, desde la superioridad jerárquica de la teología tenían que bregar con todas las dificultades que planteaba el hacer compatible la idea de un Dios creador omnipotente y "metomentodo" ${ }^{21}$ con la idea de un orden natural inmutable, condición de toda investigación científica, que ya había dado valiosos resultados que esos mismos teólogos y filósofos admiraban profundamente. Por más que respete los dogmas de la fe cristiana y haya de someterse a las directrices de ésta, Galileo ya no comparte esa jerarquización práctica del saber ni esa priorización de los problemas. Para él está claro desde el principio de su propio trayecto intelectual que el universo es un cosmos, que la naturaleza es "inexorable», «inmutable" y sigue una causalidad estricta y unívoca. Éste es su punto de partida prioritario. Desde el punto de vista puramente teórico, a Galileo el argumento de Urbano VIII le parecía sin duda el colmo de la "bella sottigliezza», inútil e irrelevante, que recriminaría irónicamente a Scheiner-Locher ${ }^{22}$. En sus Discorsi expondría claramente que, a diferencia de los calculatores medievales, lo que a él le interesaba era el conocimiento de las características del movimiento tal como se da en este mundo ${ }^{23}$. Galileo expuso detalladamente este argumento teológico en sus

${ }^{21}$ La expresión es de Funkenstein 1986, 125.

22 En las Disquisitiones mathematicae publicado por éstos se criticaba a Copérnico por las consecuencias absurdas que se derivarían, ateniéndose a la teoría copernicana de la gravedad, si el globo terrestre en su conjunto desapareciera. Galileo comentaba en el Diálogo: "La providencia de este filósofo es admirable y digna de gran alabanza, puesto que no se contenta con pensar en las cosas que podrían suceder obedeciendo al curso de la naturaleza, sino que quiere precaverse contra la posibilidad de lo que se seguiría de las cosas que sabe con toda certeza que no van a suceder nunca" (Opere VII, 268; Besomi-Helbing 1998, I, 262). Aunque Locher aparece como autor del texto, hoy ya está claro lo que se sospechaba desde hace tiempo, que el verdadero autor del texto era Scheiner. Véase Lerner 1995, 165 y 175; y Luca Bianchi 1999, 199-202.

23 «En primer lugar, conviene investigar y explicar la definición que concuerde de modo preciso con el movimiento [naturalmente acelerado] de que se sirve la naturaleza. Pues aunque no sea absurdo inventarse al propio arbitrio un cierto tipo de desplazamiento y estudiar las propiedades que de él se siguen, ... sin embargo, ya que la naturaleza se sirve de un cierto tipo de aceleración en la caída de los cuerpos graves, hemos decidido indagar sus problemas, para ver si la definición de movimiento acelerado, que según nosotros ha de darse, concuerda en realidad con la esencia del movimiento naruralmente acelerado ... En resumen, al estudio del movimiento naturalmente acelerado nos ha llevado, como cogidos de la mano, la investigación de las costumbres y normas que sigue la propia naturaleza en todas sus demás obras, en cuya ejecución acostumbra a hacer uso de los medios más primarios, más simples y más fáciles. No creo que exista nadie que crea que se 
apostillas y comentarios a un texto de Morin ${ }^{24}$. Este alude al tema de la omnipotencia divina y al grado en que la habría ejercido en distintos casos y Galileo comenta:

«Nosotros no buscamos lo que Dios podía hacer, sino lo que ha hecho. Por lo que yo os pregunto si Dios podía hacer el mundo infinito o no. Si podía y no lo ha hecho, haciéndolo finito y tal cual es de facto, al hacerlo así no ha ejercido su potencia más que si lo hubiese hecho del tamaño de una semilla de algarroba. Y si Él, para mostrar su potencia, lo hace mover en 24 horas, esto es como nada comparado con hacerlo mover en una hora muchas millas y millones de revoluciones [...] Sr. Morino, Dios podía hacer volar los pájaros con los huesos de oro macizo, con las venas llenas de mercurio, con la carne más pesada que el plomo y con alas pequeñísimas y pesadas, y así habría mostrado más claramente su potencia; podía hacer los peces más pesados que el plomo, es decir 12 o más veces más pesados que el agua; pero ha querido hacer a aquéllos de carne y plumas muy ligeras y a éstos igualmente graves que el agua para enseñarnos que Él gusta de la simplicidad y facilidad etc.» (Opere VII, 565-566).

Galileo no creía que la imposibilidad de conocer todos los mundos posibles que Dios hubiera podido crear fuera impedimento para alcanzar un conocimiento humano de este mundo que Dios eligió crear y en el que vivimos. La afirmación de que este mundo es "necesariamente ordenadísimo, es decir de partes dispuestas entre sí con sumo y perfectísimo orden" (Opere VII, 43; Besomi-Helbing 1998, I, 19) no es sólo galileana. Cualquiera que pretenda que la naturaleza es cognoscible y explicable, que es objeto de ciencia, también requiere el supuesto de una naturaleza regida por leyes. Eso significa, obviamente, que quien defiende la cosmología aristotélico-ptolemaica, esa cosmología que ahora Urbano VIII quiere proteger, también parte de este supuesto. Y Galileo quiere dejar muy cla-

puede nadar o volar de un modo más fácil y simple del que utilizan precisamente los peces y los pájaros por instinto natural» (Opere VIII, 197). Cabe recordar que estas investigaciones de Galileo, publicadas en 1638, proceden en su mayor parte del periodo comprendido entre 1602 y 1609.

24 Jean Baptiste Morin era un profesor de matemáticas de París, que en 1631 publicó su Famosi et antiqui problematis de Telluris motu vel quiete haectenus optata solutio. Galileo lo recibió cuando el Diálogo ya estaba publicado, pero lo leyó atentamente y escribió sus anotaciones en un cuadernillo. Favaro las publicó, tras el Diálogo, en Opere, VII, 562-568. 
ro este punto, cuando tras esta afirmación del orden necesario del mundo, por boca de su álter ego Salviati añade: «lo cual no creo que sea negado por vos ni por nadie", y le hace responder a Simplicio, el aristotélico defensor de la ciencia y la cosmología tradicionales:

"¿Y quién queréis que lo niegue? En primer lugar, eso es puro Aristóteles. Y, además, no parece que haya tomado su denominación sino del orden perfecto que encierra" (Opere VII, 43; Besomi-Helbing 1998, I, 19).

Simplicio alude sin duda al término griego «cosmos», que por más que refiere el mundo o universo incluye en su significado la idea de orden. Es cierto que, incluso en la investigación de este mundo ordenado que Dios decidió crear, puede plantearse el tema de la omnipotencia divina ${ }^{25}$, que se manifiesta en la grandiosidad y prodigalidad de la naturaleza. Por ello Galileo insistirá en que tampoco de este mundo pretende que pueda saberse todo. Pero si bien afirma que la naturaleza puede ser apabullante en su exuberancia y mostrarnos nuestras limitaciones para abarcarlo y la banalidad de constituirnos en medida de sus posibilidades, no es menos contundente en su convicción y afirmación de que hay cuestiones y ámbitos de la naturaleza en los que el hombre sí puede llegar a conocerla y afirmar sus conclusiones con necesidad. Del mismo modo que Galileo afirma que, en el ámbito de la matemática, el hombre puede alcanzar una certeza absoluta y un conocimiento comparable intensivamente al de Dios, (Opere VII, 128; Besomi-Helbing 1998, I, 112) también sostiene que en la medida en que la solidez de la demostración matemática puede aplicarse a las cuestiones naturales, podemos alcanzar igualmente un conocimiento seguro sobre ellas mediante demostraciones necesarias. Si Urbano VIII efectivamente leyó entero Il Saggiatore $^{26}$, pudo encontrar muchos textos en los que Galileo exponía claramente esta tesis. Por ejemplo, sólo unas páginas más allá de la fábula del sonido puede leerse el siguiente texto, a propósito de una demostración geométrica-óptica rela-

${ }^{25}$ En realidad, es posible que Galileo pensara en la cuestión más que Urbano VIII. En una primera aproximación, Bianchi ha señalado las funciones ejemplarizadora, cautelar, argumentativa y metateórica de la noción de la omnipotencia divina en los textos galileanos. (Bianchi 2000, 244 y ss.).

${ }^{26}$ Se decía que Urbano VIII no sólo se había hecho leer partes de Il Saggiatore por Ciampoli, sino que lo había leído completo. Así se lo había comunicado Rinuccini a Galileo el 2 de diciembre de 1623: "Me han dicho que el Papa (aun con todas sus ocupaciones) ha leído todo el Saggiatore con gran placer” (Opere XIII, 154). 
cionada con la naturaleza del cometa a la que había aludido el jesuita Orazio Grassi, con quien polemiza Galileo. Este último escribe:

«Pero advierta bien su caso y considere que para alguien que quiere convencer de alguna cosa, si no falsa, al menos muy dudosa, constituye una gran ventaja el poderse servir de argumentos probables, de conjeturas, de ejemplos, de cosas verosímiles e incluso de sofismas, fortificándose tras ellos y atrincherándose bien con textos claros, con la autoridad de otros filósofos, naturalistas, rétores o historiadores. Pero el someterse a la severidad de las demostraciones geométricas es un riesgo demasiado peligroso para quien no las sabe manejar; puesto que del mismo modo que ex parte rei no hay intermedio entre lo verdadero y lo falso, así en las demostraciones necesarias o se concluye sin duda posible o inexcusablemente se paralogiza, sin dejar margen a poder mantenerse en pie con limitaciones, distinciones, con distorsiones de palabras $\mathrm{u}$ otras intrigas, sino que es forzoso con pocas palabras y al primer asalto que resulte o César o nada" (Opere VI, 296).

El copernicanismo, como veremos, era según Galileo una cuestión de «o César o nada». El argumento de Urbano VIII no aniquilaba la historia del conocimiento, con sus logros unánimemente reconocidos, ni eliminaba los problemas que la ciencia natural se planteaba en su momento, ni mucho menos igualaba todas las respuestas. En el mejor de los casos era un problema teológico que ni Galileo ni ningún científico necesitaba resolver para hacer su trabajo y que por sí mismo no lo interfería. La idea griega de cosmos existía antes de que el Dios cristiano entrara en escena. Para hacerse mayor y poder ingresar en la universidad, ese Dios omnipotente había tenido que aprender racionalidad y cosmología griegas; había tenido que controlar su infantil voluntad libérrima y aprender a crear un cosmos. A principios del siglo XVII, más aún que en el siglo XIII, sólo la voluntad política podía hacer que la omnipotencia de ese Dios interfiriera en la práctica científica. El problema no era de fuerza lógica, sino de voluntad política del Papa, y ese sí era un problema peliagudo.

\section{El planteamiento de la Carta a Ingoli: 1. "O César o nada»}

En junio de 1624 Galileo partió de Roma cargado de regalos y alabanzas del Papa, que hablaba de él a los Medici como "su dilecto hijo" (Opere XIII, 184), pero eso no podía disimular que el objetivo de su viaje había fracasado. 
Así lo deja traslucir el pesimismo de su última carta desde Roma al hacer balance (Opere XIII, 182-183). Muy distintos historiadores hacen un valoración positiva del viaje basándose en el hecho de que, con ciertas condiciones, Galileo podría continuar su investigación copernicana ${ }^{27}$. Ahora bien, no creo que pueda darse por sentado como aquí parece hacerse que, después del Decreto de corrección del De revolutionibus de 1620, estuviera pública y explícitamente prohibido tratar la teoría copernicana y escribir sobre ella limitándose a los aspectos científicos "astronómicos y matemáticos". Más bien se puede afirmar que estaba explícitamente permitido, a no ser que se entienda que la única utilidad y uso posibles del De Revolutionibus que autorizaba dicho Decreto era como recurso calculístico y fuente de observaciones estrictamente para las cuestiones relacionadas con el calendario - una cuestión que tiene interés, pero en la que no puedo detenerme aquí. No dudo que, de hecho, fuera muy problemático atreverse llevar a cabo algún otro tipo de tratamiento de la teoría copernicana. Así lo demuestra el silencio de Galileo hasta más allá incluso de 1620. Pero el hecho de que con el nuevo pontificado de Gregorio XV, Galileo reiniciara sus investigaciones copernicanas y él y sus amigos en la corte papal pensaran en la posibilidad de que las enviara a Roma, también puede aducirse como corroboración de que no se trataba tanto de la letra del decreto como del espíritu que se le supusiera. Y esa era una valoración que podía cambiar según el momento y sólo podía hacerse desde la incertidumbre. Parece que en 1620-21 Galileo y sus amigos consideraban nulo el margen de maniobra que permitía el Decreto, mientras que con Urbano VIII no dudaron que se abrían más claramente las posibilidades que habían fantaseado ya bajo Gregorio XV. Pero más

27 En su biografía de Galileo, Drake escribía: «Galileo dejó Roma con garantías por parte de Urbano VIII de que era libre de escribir sobre los dos sistemas del mundo con tal que los tratara imparcialmente y no fuera más allá de los argumentos astronómicos y matemáticos de ambos lados» (Drake 1978, 291). D’Addio considera positivo el balance del viaje. Según su versión, Galileo "había conseguido resultados de relieve" (D'Addio 1993, 122). Se refiere a la rebaja teológica de Urbano VIII y a la posibilidad del tratamiento hipotético del copernicanismo. Bucciantini incluso parece considerar el viaje como un claro éxito. Comenta que tras saber de los comentarios sobre el copernicanismo hechos por el Papa al cardenal Zollern, Galileo decidió marcharse de Roma, y continúa: "Ahora ya no había ninguna razón para seguir en Roma. Lo que deseaba se había verificado puntualmente: la interpretación que el Papa Barberini daba de la condena de Copérnico no estaba alejada de la posición que ya habla asumido en las discusiones que llevaron a la publicación del Decreto: las investigaciones sobre el sistema copernicano podían pues continuar y, con ciertas condiciones, podian publicarse" (Bucciantini 1995, 157). 
que de "garantías" seguía tratándose de riesgo asumible. Y comparado con las esperanzas que había albergado Galileo, creo que difícilmente puede hablarse de éxito de su viaje. Sin duda era positivo para Galileo que Urbano VIII hubiera hecho una interpretación suavizada de la calificación teológica de la condena del copernicanismo, pero también es cierto que esta rebaja teológica tenía como contrapartida que los documentos, y concretamente el Decreto de condena de 1616, no se habían modificado en absoluto, ni Urbano VIII pensó en ningún momento en comprometerse por escrito con su nueva interpretación, emanando algún tipo de matización oficial y pública. La situación objetiva, documental, no había cambiado nada. Por más que no hay por qué dudar de que en aquel momento Urbano VIII era sincero en sus afirmaciones, también es indudable que tener que jugar con el margen de permisividad que sus palabras, dichas en un momento de euforia, parecían autorizar, era una apuesta muy arriesgada. Por tanto, la aparente concesión iba acompañada de un aumento potencial de peligrosidad. Por otra parte, no hay duda de que Urbano VIII mostraba una simpatía y una deferencia personal hacia Galileo y su trabajo que Pablo V no había tenido nunca. No obstante, estos elementos positivos venían contrapesados por la firmeza de la convicción del Papa respecto a la indemostrabilidad de la teoría copernicana. Y este aspecto era tan crucial como problemático, como lo era también el hecho de que el Papa consideraba el copernicanismo un asunto menor.

No es extraño que esta situación resultara deprimente para Galileo. No sólo no había conseguido una revisión de la condena del copernicanismo, sino que cualquier iniciativa que decidiera tomar dependía total y absolutamente del veleidoso humor de Urbano VIII que en aquellas cuestiones estaba muy lejos de la coherencia. No era nada fácil explicar que el Papa pudiera postular tan orgulloso el escepticismo a partir de su argumento teológico y, a la vez, leyera con placer y sin mostrar ningún rechazo Il Saggiatore. Se trataba de una obra que desde luego se caracteriza más por su rechazo del principio de autoridad, por su imagen de una naturaleza inexorable y estructurada matemáticamente, reivindicando las demostraciones necesarias y el recurso a la experiencia como únicos medios para alcanzar conocimientos frables sobre el universo, que por el escepticismo conclusivo de la fábula del sonido, que estaba muy lejos del defendido por el Papa. Desde el punto de vista personal, eso podía entenderse como generosa flexibilidad por parte de Urbano VIII, como una graciosa concesión que surgía del aprecio y el entusiasmo del momento. Pero teórica y argumentalmente era una 
incoherencia flagrante, lo que como base de una relación o un acuerdo sobre el proyecto de Galileo resultaba sumamente problemático. Galileo sabía que tendría que explorar esta incoherencia, y a pesar del fracaso del objetivo de su viaje, estaba dispuesto a jugar con las cartas que le dieran. La actitud de Urbano VIII implicaba que el juego era el equívoco. No había otro modo de establecer las reglas que jugando, y Galileo decidió envidar.

Quizás incluso antes de su regreso a Florencia, Galileo había decidido explorar los difusos límites y posibilidades del tratamiento del copernicanismo que le ofrecía la nueva situación contestando a la Disputatio de situ et quiete Terrae de Francesco Ingoli, al que en 1616 no había podido dar cumplida respuesta. La Carta a Ingoli de Galileo constituye un órdago en todos los sentidos y a diferencia de Il Saggiatore no es una obra planeada colectivamente en la Accademia dei Lincei ${ }^{28}$. Muy al contrario, Galileo la ha pensado y redactado en solitario porque tiene muy claro cuál ha de ser el enfoque y la concreción. Es su apuesta y, en cierto sentido, no quiere interferencias ${ }^{29}$. No se trata sólo de que Galileo refute uno por uno los argumentos astronómicos y fisicos de Ingoli y ponga de manifiesto su paralogismo - Ingoli no se da cuenta de que en muchos casos parte del supuesto de que la Tierra está quieta en el centro del universo, que es precisamente lo que está en discusión-, sino que en ocasiones la conclusión copernicana está

${ }^{28}$ Durante la estancia de Galileo en Roma, Giovanni Faber, un miembro de la Accademia dei Lincei le escribía a Cesi: “Me he puesto a su disposición en todo lo que pueda hacer por él, pero no me ha comentado nada de sus asuntos" (Opere XIII, 178). Está claro que el decepcionado Galileo apenas hablaba del objetivo de su viaje ni siquiera con los que se se supone que compartían sus cuitas. Poco antes de que Galileo partiera de Roma, el 1 de junio de 1624, Faber aludía de nuevo a la cuestión, comentaba la amistad de Galileo con el cardenal Zollern, que Riccardi aunque bien dispuesto aconsejaba no desenterrar la disputa copernicana, y ańadía: "Por lo que creo que el sr. Galileo imprimirá alguna cosita que aluda (dica il fatto) indirectamente a la cuestión, de modo que los enemigos no tengan donde agarrarse" (Opere XIII, 181). Es obvio que Galileo no se mostró muy explícito respecto a sus planes, porque lo que decidió escribir, la Carta a Ingoli, estaba muy lejos de poder considerarse "una cosita".

${ }^{29}$ Algunos detalles parecen indicar que Galileo escribe su réplica a Ingoli sin contar con el parecer de los linceos. De hecho sólo informa a Cesi sobre la Carta a Ingoli a finales de septiembre, cuando ya la ha terminado y la va a enviar a Roma. Cesi, que había estado muy ocupado con sus asuntos en Roma y sobre todo con el parto de su mujer, contesta inmediatamente que la espera con ansia, "deseando también entender el por qué de ésta y cómo se ha decidido a escribirla en estos momentos. Igualmente espero y ansío la obra del flujo y el reflujo, tema verdaderamente admirable, y alabo que avance en ella lo más posible» (Opere XIII, 219-220). 
expresada con una claridad sorprendente ${ }^{30}$. A lo largo de estas páginas Galileo introduce toda una serie de argumentos decisivos contra la cosmología tradicional y favorables al copernicanismo, que después desarrollará en el Diálogo. Pero Galileo no se limita a los argumentos de física o astronomía. De hecho, sorprendentemente, aquí encontramos una réplica directa e inmediata al argumento de Urbano VIII, cuando escribe:

"Pero tratándose de los dilemas más importantes y que necesariamente deben ser de este modo o del otro y en los que no se puede recurrir a un tercer caso, como son precisamente si el Sol se mueve o está quieto, si la Tierra se mueve o no, si está en el centro o fuera de él, si el orbe estrellado gira o está inmóvil, de éstos se pueden hacer afirmaciones con cierta resolución y las conclusiones afirmadas sobre ellas no quedan sometidas después a cualquier novedad concreta que se descubra u observe en los movimientos propios de los planetas" (Opere, VI, 534).

De nuevo y más contundentemente el "o César o nada», que en principio es el planteamiento más radicalmente opuesto a las infinitas posibilidades que, según Urbano VIII, nos incapacitan para conocer el sistema del mundo. Pero hay más.

\section{El planteamiento de la Carta a Ingoli:}

\section{La irreflexión convertida en conocimiento tácito}

Recordemos que la propuesta de Ingoli para la Corrección del De revolutionibus afirmaba que los textos de Copérnico eran asumibles y podían permitirse en tanto que hipotéticos, pero explicaba claramente que en ningún caso se trataba de "hipótesis» susceptibles de contrastación, confirmación o refutación, sino por el contrario de hipótesis puramente ficticias o falsas utilizables como mero

30 «Si algún lugar en el mundo puede llamarse su centro, es sin duda el centro de los giros celestes; y todo el que entiende de estas materias sabe que en éste se encuentra el Sol y no la Tierra" (Opere VI, 539). Y unas páginas más adelante, al aludir a los argumentos tradicionales contra el movimiento diurno esgrimidos por Ingoli, Galileo señala que si acaso benefician a Copérnico, pero añade: «Pero os digo más, tengo otras experiencias no observadas hasta ahora por nadie, las cuales (permaneciendo dentro de los límites del discurso humano y natural) necesariamente convencen de la certeza del sistema copernicano. Pero todas estas cosas, dado que para su explicación requieren de consideraciones más amplias, las reservo para otro momenton (Opere VI, 543) 
instrumento de cálculo. Hemos visto que dicha propuesta fue aceptada unánimemente por los cardenales en 1618, tras la consulta de los matemáticos jesuitas. No obstante, el Decreto publicado en 1620 no incorporaba el texto de Ingoli. En su lugar la lista de textos corregidos iba precedida de una "advertencia (monitum) al lector de Nicolás Copérnico» mucho más escueta. En ella se dice que a pesar de que se había decidido prohibir los escritos de Copérnico porque éste no se limitaba a "tratar hipotéticamente (per hypothesim), sino construir como muy verdaderas" las cuestiones relativas la ubicación y movimiento de la Tierra, contrarias a las Sagradas Escrituras, dada la utilidad de dichos escritos para la República eclesiástica, los cardenales de la Congregación «llegaron por acuerdo unánime» a la decisión de permitir su circulación siempre que los pasajes en los que se discute no hipotéticamente (non ex hypothesi) el movimiento terrestre fueran corregidos tal como se indicaba. Así pues, dado que el Decreto público no precisaba el sentido que debía darse al tratamiento hipotético de la teoría copernicana, jabría la posibilidad de tratarla como una hipótesis no ficticia o falsa por principio, sino corroborable, aunque no corroborada? En mi opinión está claro que, en 1620, la Congregación del f́ndice daba por sentado que la respuesta era negativa y que así fue entendido por todos. Pero lo cierto es que cuando el cardenal Maffeo Barberini, que pertenecía a dicha Congregación, fue elegido Papa la situación se planteó en términos diferentes por dos razones. La primera es que, como hemos visto, Urbano VIII priorizó un planteamiento teológico-epistemológico diferente del formulado por Ingoli. La segunda es que Galileo supo aprovechar esto para abrir aquella posibilidad insospechada.

Efectivamente, en las primeras páginas de la Carta a Ingoli Galileo deja muy claro que sólo se rinde al argumento teológico de Urbano VIII, pero de ningún modo a la tesis filosófica de Ingoli que la Iglesia había adoptado. Al principio del texto explica las razones por las que, después de ocho años, se decide a contestar, y advierte que no lo hace con la intención de afirmar la verdad del copernicanismo "que ya ha sido declarado como sospechoso y repugnante a aquella doctrina la cual por majestad y por autoridad es superior a las disciplinas naturales y astronómicas" (Opere VI, 510). Podemos pensar que se refiere tanto, en general, a la interpretación teológica adoptada por la Iglesia, como al argumento de Urbano VIII en particular. Pero aclarado de entrada que el criterio para el abandono del copernicanismo es puramente teológico, Galileo se permite hablar con toda libertad del ámbito estrictamente natural. Es decir, rendido a Urbano VIII, se las va a tener ahora con Ingoli en su papel de asesor científico. Quiere mos- 
trar que si había sido copernicano no era porque no conociese o no entendiese las críticas que Ingoli había planteado. Eso sería suponerle muy obtuso, dice, y en este punto, al explicar por qué contesta a Ingoli, su texto sigue así:

"Añádese otra razón, y es que habiéndose atribuido no poca consideración a estas razones aducidas por vos, incluso por parte de personas de tanta autoridad que han podido espolear el rechazo de la opinión copernicana decidido por la Congregación del Indice y habiendo llegado, por lo que oigo, tales escritos a varias naciones ultramontanas y acaso también a manos de los herejes, me parece conveniente para mi repuración, y para la de muchos otros, el quitarles la ocasión de tener hacia nuestro saber menor consideración de la que se le debe, como si entre los católicos no hubiera habido quien supiera que en estos escritos [la Disputatio de Ingoli] se pueden echar muchas cosas en falta, o bien como si la refutación de la opinión de Copérnico se hubiese aceptado basándose en la confianza en ellos, sin temer en absoluto que ya nunca pudiera suceder que alguno de los que están separados de nosotros pueda aportar alguna demostración concluyente y segura o alguna experiencia manifiesta de su [la de Copérnico] verdad. Y añado además que, para confusión de los herejes entre los cuales oigo que los de mayor prestigio son todos de la opinión de Copérnico, tengo intención de tratar este tema bastante extensamente y mostrarles que nosotros los católicos no seguimos en la antigua certeza que nos enseñaron nuestros sagrados autores por falta de razonamiento natural o por no haber visto cuantos argumentos, experiencias, observaciones y demostraciones hayan visto ellos, sino por la reverencia que tenemos a los escritos de nuestros Padres [de la Iglesia] y por el celo de la religión y de nuestra fe. De modo que cuando vean que nosotros hemos entendido perfectamente todos sus argumentos astronómicos y naturales y además otros aún de bastante mayor fuerza que los presentados hasta ahora, a lo sumo podrán evaluarnos como personas constantes en nuestra opinión, pero no ya de ciegos e ignorantes de las disciplinas humanas, lo cual en definitiva no debe importar a un verdadero cristiano católico. Me refiero a que un hereje se ría de él porque anteponga la reverencia a la fe que se debe a los autores sagrados a cuantos argumentos y experiencias tienen todos los astrónomos y filósofos juntos. Añádese a éste otro beneficio para nosotros, que será el comprender cuán poco se debe confiar en los razonamientos humanos y en la humana sabiduría y por ello cuán obligados estamos a las ciencias superiores, que son las únicas capaces de despejar la ceguera de nuestra mente y de enseñarnos aquellas disciplinas 
a las cuales nunca llegaremos mediante nuestras experiencias y argumentos" (Opere VI, 511-512; cursivas mías).

Realmente la habilidad de Galileo es apabullante, pero su apuesta era muy alta. Ya no se trata únicamente de que a lo largo de la Carta a Ingoli, como acabamos de ver, acumulara argumentos pro copernicanos y planteara algunas cuestiones centrales de la polémica cosmológica en términos del tercio excluso, que en principio era difícilmente compatible con el planteamiento de Urbano VIII. Aquí es la propia acepción del término «hipótesis» la que se plantea y es ahí donde se hace comprensible su atrevimiento. Galileo introduce alguna cláusula de cautela. Nos dice que los nimios argumentos de Ingoli no pueden evitar el temor de que "pueda suceder" que alguien ofrezca "una demostración concluyente y segura o alguna experiencia manifiesta» de la teoría copernicana. Pero aún así y por remota que pueda parecer la posibilidad, en el primer texto en cursiva de la cita la teoría copernicana se entiende como una hipótesis susceptible de demostración y de corroboración empírica. Galileo no está afirmando únicamente que los argumentos de Ingoli son pedestres y no refutan la teoría copernicana, sino que al hacerlo atribuye a ésta un estatus teórico de hipótesis en principio verificable que en 1620 se le había negado. La apuesta consistía en desplazar el nivel de neutralización de las pretensiones de verdad de la teoría, de sus demostraciones y pruebas, a un nivel distinto y superior, el teológico, que ahora aparece como independiente. El envite de Galileo es tan sutil como osado. Es exquisitamente sutil porque no adopta una versión posible pero muy peliaguda del argumento de Urbano VIII y de sus consecuencias que vendría a decir: puesto que el argumento prueba la indemostrabilidad de la teoría copernicana, no importará que el propio Galileo u otros intenten demostrarla y propongan argumentos, experiencias y demostraciones, mientras el Papa se sienta sonriente a ver pasar los cadáveres de sus intentos fallidos. Esta interpretación no era adecuada porque exigía que los intentos de corroboración de la teoría fracasaran desde los propios criterios científicos. Galileo no podía ni quería exponerse a la posibilidad de que los argumentos y demostraciones fueran ganando terreno en la comunidad científica, como él estaba convencido de que sucedería, y eso constituyera un desafío al argumento del Papa. No, la interpretación de las implicaciones del argumento de Urbano VIII que explicita en este texto es muy diferente: ya a priori no importan las pruebas y demostraciones que los científicos hallen y den por buenas. Eso no obstará para que nunca se pueda saber con certeza si lo que ellos consideran verdadero, acorde con los hechos, en verdad responde a cómo 
Dios hizo y dispuso el mundo realmente, porque la noción de la omnipotencia divina lo impide. Las demostraciones necesarias y las pruebas experimentales de los científicos, por sólidas que sean desde sus propios criterios, pertenecen al limitado nivel del conocimiento humano, que es inconmensurable con el de Dios. Es decir, los criterios de la comunidad científica están subordinados y sometidos a los de la teología, que ya ha dictaminado sobre el asunto ${ }^{31}$. Esta lectura del argumento papal permite a Galileo moverse con total soltura en el plano puramente científico. No hay ninguna cortapisa para que él analice en profundidad los pros y los contras de la teoría copernicana y la tradicional. Más aún, él no sólo dice que conoce "cuantos argumentos, experiencias, observaciones y demostraciones» han presentado hasta entonces los herejes en favor del copernicanismo, sino que afirma que tiene otros "de bastante mayor fuerza" que prueban la certeza del sistema copernicano. Así pues, Galileo afirma sin tapujos que en el ámbito del conocimiento humano, es decir, desde un punto de vista cientifico, tiene argumentos que no sólo refutan las críticas tradicionales sino que aportan clara evidencia en favor del copernicanismo. Naturalmente Galileo sólo puede afirmar esto como preparación para la apoteosis formalmente oresmiana final ${ }^{32}$, en la que la aparente transgresión se convierte en desafiante piadosa virtud. El intento de refutación del copernicanismo que había hecho Ingoli no sólo era fallido por su obvia incompetencia científica, sino porque no había

31 Desde esta interpretación del argumento de Urbano VIII por parte de Galileo, la diferencia entre el escepticismo de Bellarmino y el de Urbano VIII sería fundamental. La incredulidad de Bellarmino en la posibilidad de hallar una demostración de la teoría copernicana era intracientífica. Bellarmino creía que la ciencia no podía llegar a tal demostración. No se trataba, como en el caso de Urbano VIII tal como lo explicitaba Galileo, de que, dijera lo que dijera la ciencia, la teología garantizaba su incertidumbre e irrelevancia respecto a un auténtico conocimiento del mundo. Era una verdad pura que no necesitaba de los hechos ni podía verse afectada por éstos.

32 Efectivamente estas declaraciones traen a la memoria el famoso texto de Oresme, en el que tras exponer una apabullante lista de argumentos contra las críticas a la posibilidad del movimiento terrestre y las ventajas de su postulación concluye: "Y a pesar de todo, todos sostienen, y yo también lo creo, que se mueven los cielos y no la Tierra: Pues Dios afirmó el orbe de la Tierra, que no se moverá [Salmo XCII, 1]. Esto a pesar de los argumentos en contra, porque son argumentos claramente no concluyentes. Sin embargo, después de considerar todo cuanto se ha dicho, se podría creer que la Tierra es la que se mueve y no el cielo, pues lo contrario no es claramente evidente. Sin embargo, esto prima facie parece tanto o más contrario a la razón natural que todos o la mayor parte de los artículos de nuestra fe. De este modo, todo lo que he dicho de esta manera por diversión o como ejercicio intelectual puede servir como un valioso medio para refutar y refrenar a aquéllos que quisieran impugnar nuestra fe mediante argumentos." En Grant (Ed.) 1974, pág. 509-510. 
visto dónde radicaba realmente la auténtica refutación. A diferencia de Ingoli, Galileo podía aceptar, mostrar e incluso reforzar las pruebas en favor del copernicanismo, los hechos y argumentos que fortalecían la convicción de su certeza, porque su indemostrabilidad y la imposibilidad de sus pretensiones de verdad no dependian de su corrección o incorrección desde los criterios científicos, sino de los límites radicales que caracterizaban dichos criterios, es decir, de los límites propios del conocimiento humano. Más aún, cuanto más claramente se mostrara la corrección "científica» de la teoría heliocéntrica más evidente se haría, para desconcierto de los herejes, la fortaleza y la fe del Papa, de Galileo y de todo buen cristiano en el criterio teológico. A Galileo le podrían acusar de tozudo en la fe, pero no de ignorante. Podrían acusarle de no ser consecuente, de ser irracional, pero eso era un problema del pobre hereje que concebía la prioridad de la fe como una carga y no gozaba del "beneficio" de haber comprendido "cuán poco se debe confiar en los razonamientos humanos y en la humana sabiduría». Sólo la ciencia superior de la teología puede "despejar la ceguera de nuestra mente», o lo que es lo mismo en este caso, el argumento de Urbano VIII nos sitúa en un plano que no se mezcla con la ciencia natural, sino que está por encima de ella. No resulta extraño que algunos historiadores hayan supuesto que tal audacia sólo era posible con el consenso explícito del Urbano VIII ${ }^{33}$. Pero lo cierto es que si nos preguntamos qué fue lo que autorizó o pudo autorizar exactamente Urbano VIII nos damos cuenta de que la respuesta no está nada clara. Porque, a mi entender, es obvio que no autorizó ese texto concreto de Galileo, ni siquiera esa versión concreta del enfoque de la cuestión. En cuanto a las directrices generales, ¿podemos afirmar que el Papa había querido ir conscientemente más lejos que los decretos de 1616 y 1620 que no había querido modificar en su letra? Eso forma parte del problema que, en mi opinión, hay que plantear de otro modo.

\section{Urbano VIII... quievit}

Todo lo que había dicho Galileo hasta el momento respecto a la relación entre ciencia y teología y sobre la capacidad y alcance del conocimiento huma-

${ }^{33}$ Santillana, por ejemplo, comenta: “Una audacia semejante, seguida de sesenta páginas de pruebas apremiantes y expresadas sin dudas, es difícil concebirla sin la autorización explícita de Urbano VIII.» Santillana 1960, 333. Drake va más allá e incluso sugiere que el propio Papa habría animado a Galileo a responder a Ingoli. Drake 1978, 291. 
no está muy lejos de lo que dice en este texto ${ }^{34} \mathrm{y}$, por tanto, no tiene mucho sentido plantearse si Galileo creía realmente lo que argumentaba literalmente aquí. Después de 1616, en las manifestaciones públicas en este tema, como en muchos otros hacía tiempo, no se trataba, no podía tratarse de expresar las propias convicciones. El criterio era la ortodoxia, no la sinceridad. La pregunta que sí tiene interés es más bien si Urbano VIII lo creía, es decir, si este planteamiento de Galileo respondía y se correspondía realmente con la visión de la cuestión que tenía el Papa. El objetivo de Galileo, la finalidad de su argumentación son claros: poder trabajar de nuevo en el marco del copernicanismo. ¿Qué era lo que pretendía o exigía Urbano VIII en relación a esta cuestión? No lo sabemos. Y en mi opinión, él tampoco lo sabía con claridad ${ }^{35}$. Es decir, una vez enunciado su argumento, ¿qué consecuencias teóricas y prácticas tenía, según él, en el trabajo científico? Creo que todo indica que Urbano VIII jamás se planteó seriamente este aspecto de la cuestión. Las alusiones de Galileo a sus audiencias con el Papa y, en general, su correspondencia durante su estancia en Roma no sólo no aclaran o siquiera mencionan el asunto, sino que inducen a pensar que ésa era precisamente la gran incógnita. Lo único que sabemos es que Urbano VIII no quería dejar sin respuesta las críticas de los protestantes, que era el único aspecto por el que mostró interés. Por eso los amigos linceos de Galileo hacían cábalas sobre qué era lo más acertado hacer, sobre cómo tantear las posibilidades de acción y su adecuado planteamiento ${ }^{36}$. Pues bien, lo que hacía Galileo

${ }^{34}$ Basta recordar lo dicho por él en la Carta a Castelli y en la Carta a Cristina de Lorena, en las que si bien defendía la independencia entre teología o Escrituras y ciencia, sugería que si acaso las teorías demostradas podían servir para la correcta interpretación de los textos bíblicos relacionados (Opere V, 283-284).

${ }^{35}$ Los decretos habían establecido ya lo que no podía hacerse: afirmar la verdad de la teoría copernicana; y lo que podía hacerse: usarla como hipótesis de cálculo. Pero no estaba nada claro qué podía querer decir tratar la teoría copernicana al margen del calendario. Y la pregunta que se plantea es qué novedad introducía en esta situación el argumento que Urbano VIII expone como decisivo. ¿Permitía hacer algo nuevo o diferente de lo que permitían los decretos de 1616 y 1620 ? ¿Permitía un modo distinto de hacerlo, fuera el que fuera? Ese es el tipo de cuestiones que, en mi opinión, Urbano VIII no había pensado seriamente y, sin embargo, Galileo explota.

${ }^{36}$ En su carta de 8 de noviembre de 1624 Guiducci le comenta a Galileo: «Esta mañana que he ido a verlo [a Ciampoli] para recuperarla [la Carta a Ingoli], me dijo que quería pediros permiso para arreglar dos frases que, por más que están bien y no contienen nada malo, le parece que podrían ser censuradas y, a primera vista, podrían provocar ideas distintas de las que se pretende. Se trata de aquéllas en las que se dice que a un buen católico no ha de importarle que un herético se ría etc., en las que no pretende cambiar el sentido, sino presentarlo con palabras un poco más 
aquí, aprovechando esa preocupación política del Papa, era llenar de contenido la etérea reflexión de Urbano VIII y exponer una serie de afirmaciones teóricas y algunas consecuencias prácticas como si fueran no ya una deducción posible, sino el derivado inmediato y natural, casi una mera ilustración de lo dicho por el Pontífice. Con su funambulismo retórico, la temática de la omnipotencia divina y la superioridad de la teología en la jerarquía disciplinar pasan así de aparecer como una dificultad para la investigación científica a convertirse en sus mejores garantes. La ciencia natural puede decir lo que quiera desde sus propios criterios porque sus conclusiones son y están subordinadas por definición a la teología, pertenecen a un nivel inferior. $Y$ Galileo pasa a ejercer directamente esa libertad exponiendo su investigación científica en lo que sigue de la Carta a Ingoli. La dimensión política es muy útil para fortalecer la estrategia: naturalmente no tiene ninguna pretensión de reivindicar o alcanzar la verdad, sólo lo hace para mostrar a los herejes que los católicos, en realidad algunos católicos ${ }^{37}$, no son tontos sino piadosos. Lo cierto es que Galileo se mueve en las arenas movedizas que había arrojado Urbano VIII como si fuera llevado plácidamente por las límpidas aguas de un manso río. El Papa había dejado un estrechísimo margen, difícilmente transitable, es cierto, pero ¿cómo acusar a Galileo que transitara por él como si fuera la anchurosa Via della Conciliazione, que lleva a la plaza de San Pedro? Donde parecía que pendía de un hilo, Galileo daba la impresión de que hacía acrobacias asegurado por gruesas maromas. Un aspecto básico de la cuestión era que, fuera cuál fuera la reacción de Urbano VIII, tanto si éste callaba como si argüía en uno u otro sentido, se estaría definiendo respecto a la cuestión más de lo que lo había hecho, sin haber pensado hacerlo o incluso sin desear hacerlo. La equívoca indefinición que había lanzado le venía devuelta como opción delimitada sobre la que cualquier reacción suya equivaldría a un pronunciamiento. Ahora el Papa era el único que podía decidir si Galileo le había interpretado bien y si se había movido dentro de los límites trazados por él.

seductoras (speciose) y que no puedan despertar sombra alguna de duda en las personas mal dispuestas" (Opere XIII, 226). Pero por lo que sabemos, Guiducci nunca llegó a recibir las correcciones de Ciampoli y Galileo jamás quiso introducirlas por sí mismo como le sugirió Guiducci (Opere XIII, 229 y 242), y el texto nos ha llegado sin ellas.

37 Esta es una diferencia crucial entre este texto de Galileo y el del inicio del "prefacio" al Diálogo (Opere VII, 29; Besomi-Helbing 1998, I, 5) que le fue impuesto por el Papa (Opere XIX, 327), pero no puedo detenerme aquí en este punto. 


\section{Por circunstancias que no necesitamos exponer aqui ${ }^{38}$, la Carta a Ingoli final-} mente no fue entregada a Ingoli, pero sí llegó a quien podía considerarse su auténtico destinatario, es decir a Urbano VIII. Ciampoli cuenta a Galileo:

"Leí la respuesta que disteis a Ingoli y también le expuse gran parte a Nuestro Señor [Urbano VIII], que gustó mucho del ejemplo de la criba y de los cuerpos graves que se consideran poco aptos al movimiento, con las graciosas experiencias que V. S. aporta" ${ }^{39}$.

${ }^{38}$ El anuncio de las críticas de Chiaramonti, las maniobras de Grassi y, posteriormente, los rumores de una denuncia anónima contra Il Saggiatore aconsejaron parar la distribución de la Carta a Ingoli.

39 Opere XIII, 295. Fantoli plantea dudas sobre la aprobación de la Carta a Ingoli por parte del Papa al afirmar que «es probable que Ciampoli hubiera elegido hábilmente las partes que no corrían peligro de herir la susceptibilidad del Papa y por tanto no se podía deducir demasiado de esta reacción suya favorable" (Fantoli 1997, 307). Es cierto que Ciampoli había sugerido modificar dos frases de dicho texto por miedo a que pudieran ser censuradas o por su posible mala interpretación por parte de los malintencionados, pero Guiducci especifica que esas dos frases «son aquellas de que a un buen católico no ha de importarle que un hereje se ría etc." (Opere XIII, 226). Es decir, las dos frases siguientes: "lo cual en definitiva no debe importar a un verdadero cristiano católico. Me refiero a que un hereje se ría de él porque anteponga la reverencia a la fe que se debe a los autores sagrados a cuantos argumentos y experiencias tienen todos los astrónomos y filósofos juntos." Como puede verse, aunque las dos cuestiones no sean independientes, Ciampoli no está poniendo en cuestión la interpretación que hace Galileo del argumento papal y del papel de las ciencias superiores. Éste era el punto básico de partida de la Carta a Ingoli y el elemento crucial de la exploración que hacía Galileo, y cuestionarlo hubiera equivalido a renunciar a la Carta en su totalidad. De lo que se trataba era de ver qué decía y cómo reaccionaba el Papa en este punto, sin el cual todo lo demás no tenía sentido. Lo que preocupa a Ciampoli es un problema que por una parte tiene componentes personales, que el Papa pueda pensar que alguien puede reírse de él y que Galileo dé una imagen de católico sin fisuras, y por otra políticos, que los protestantes puedan utilizar este punto contra el Papa y contra la Iglesia católica. Por otra parte, sabemos por Guiducci que Ciampoli había pasado la Carta a Ingoli a algunos amigos y que uno de ellos, Giorgio Conneo, el 22 de noviembre de 1624 había hablado de ella con el cardenal sobrino Francesco Barberini, ante el que habia censurado a Ingoli por escribir de cosas que no sabia y habia alabado a Galileo por fustigarlo después de mucha contención. Guiducci nos cuenta más. Al enterarse de que Galileo le había replicado, Ingoli le había pedido una copia de la Carta a Ingoli, pero Guiducci se había negado a dársela porque no tenía autorización para entregarla a nadie sin permiso. Guiducci sabia que Ingoli estaba tratando de conseguir una copia y en este punto decia: «Monseñor Ciampoli ya habia hablado antes de ello con Nuestro Señor [el Papa] y había convencido a Su Santidad de que estaba bien reprimir la audacia de gente de esta clase, que se pone a escribir de lo que no entiende en perjuicio de la reputación de las Congregaciones de aqui. La gestión ha sido hábil, puesto que habiendo preparado el terreno, si el otro se quejara, hallaria a Su Santidad debidamente informado" (Opere XIII, 230; cursiva mía). Esta información de Guiducci pone de manifiesto que 
Es obvio que eran buenas noticias. De hecho, teniendo en cuenta que Urbano VIII era tan hablador como dubitativo ${ }^{40}$ difícilmente podían ser mejores. $\mathrm{El}$ simple hecho de que Urbano VIII no hubiera puesto ninguna pega concreta al planteamiento de Galileo, el que no se hubiera negado a una u otra afirmación, el que no quisiera aclarar que no se le había entendido del todo bien o pretendiera matizar algún aspecto era ya una buena noticia. Podría pensarse, no sin razón, que se repetía aquí la misma paradoja que en el caso de Il Saggiatore; que el Papa se permitía de nuevo admirar partes concretas de un texto que, en principio y globalmente, podía ser fácilmente objetable y que en lo sustantivo entraba en contradicción con sus ideas. Pero, y ahí radica la habilidad de Galileo, esa lectura sólo podía hacerse si no se tomaba debidamente en serio el argumento papal y se prejuzgaba que lo realmente importante era lo que los científicos hicieran y dijeran en la práctica, y no el que la omnipotencia divina garantizaba la inutilidad de sus esfuerzos. Y era difícilmente censurable que Galileo se tomara el argumento del Papa muy en serio ${ }^{41}$. En aquella situación, Galileo no necesita-

el asunto tratado en el párrafo citado había sido comentado directamente al propio Papa por Ciampoli. Así pues, incluso antes de que Ciampoli le expusiera gran parte de la Carta a Ingoli, el tema problemático del texto de Galileo era conocido por Urbano VIII. Por tanto, no parece que en ningún caso pueda pensarse que el párrafo citado que vengo comentando pudiera ser uno de los textos que Ciampoli pudiera eludir en su exposición al Papa.

${ }^{40}$ En octubre de 1623 el embajador de Este comentaba que "en su gestión ordinaria Nuestro Señor [Urbano VIII] ha sido siempre de mucho hablar y con la vivacidad de su intelecto sugerir argumentos sin resolver nunca nada, al menos la primera vez) (Cirado en Pastor 1948, Tomo XIII, vol. XXIX, 318-319; Ranke 1993, 465-466).

${ }^{41}$ En última instancia la fortaleza del argumento papal radicaba en la fe que uno le atribuyera. Si los científicos, en este caso Galileo, no pretendían que habían probado la contradicción de todas las demás posibilidades cosmológicas viables en la mente de Dios y no afirmaba su verdad, como obviamente Gailieo no haría, ¿cuál podía ser la dificultad de que los cientificos utilizaran sus limitados criterios? El que alguien se riera de esta opción podía considerarse una grave falta de respeto, acaso una herejía, pero del mismo carácter que la negación o ridiculización de cualquier otro dogma de la Iglesia. En ningún caso podía temerse o considerarse como una refutación, y si alguien consideraba que sí lo hacía, estaba renunciando al argumento papal, aceptando su invalidez y su vacuidad. Es posible que Ciampoli creyera que efectivamente el argumento era una sutileza irrelevante, como Galileo, y por eso quisiera suavizar lo más posible la formulación del tema del desprecio de las risas de los herejes. En realidad, es muy dificil determinar en que hubiera podido consistir la suavización propuesta por Ciampoli respecto a las pullas de los protestantes si, como él mismo dice, se aceptaba el planteamiento teológico-epistemológico que hacía Galileo del argumento papal. Todo parece indicar que Ciampoli simplemente no quería que el Papa pudiera imaginarse objeto de irrisión. Ciampoli tomaba en cuenta dos aspectos psicológicos y los priorizaba de un modo muy claro: estaba más preocupado por la susceptibilidad del Papa ante una posible 
ba decidir si Urbano VIII suscribía totalmente el desarrollo que había hecho de su argumento, si estaba admirando cuán proteico era el contenido de sus propias ideas, que ahora le mostraba Galileo, o qué pasaba en realidad por su cabeza. La bruma impenetrable de la mente del Papa en esta cuestión era el medio en el que Galileo estaba condenado a moverse, tratando de avanzar. Por el momento había dado un paso importante: el Papa no había puesto ninguna dificultad a su arriesgado sondeo y sus alabanzas concretas podían ser vistas como el refuerzo de una aprobación explícita. Ni siquiera había que suponer que ahora se había invertido la situación y, parafraseando el final de la cita de Oreggi, que «oídas aquellas cosas... aquel hombre doctísimo (en este caso Urbano VIII) se conformó (quievit)". No, lo que se suponía que había sucedido era que Galileo simplemente reflejaba, aumentados, los ecos de la ráfaga argumental lanzada por el Papa en 1616/1624; se había limitado a exponer, desarrolladas, las ideas del propio Papa. Su silencio de entonces y el silencio de Urbano VIII ahora tenían el mismo contenido y la misma elocuencia. Galileo simplemente había reiterado y explicitado su mutua conformidad. Así pues, como exploración de los difusos límites de la situación, la Carta a Ingoli había resultado un éxito y había razones para pensar que el Diálogo, cuya redacción anunciaba Galileo al final de la Carta a Ingoli, podría seguir el mismo camino. Todo dependía de la firmeza del Papa en «sus" propias convicciones. Lo cierto es que los documentos de 1616 y 1620 no habían sido formalmente modificados, pero no había otra alternativa que confiar en la seguridad en sí mismo que mostraba Urbano VIII cuando había tomado una decisión, incluso frente a las disposiciones de papas anteriores ${ }^{42}$.

burla, que seguro de la fuerza de su convicción en la contundencia lógica su argumento. Pero la propuesta de Ciampoli ya implicaba ceder en lo fundamental atribuyendo al Papa una inseguridad que hasta ahora no había mostrado en absoluto y, en el mejor de los casos, tan sólo introduciría mayor confusión y añadiría equívoco al equívoco. Todo lo que fuera acentuar esa línea era indicarle implícitamente al Papa que su postura era poco seria, y eso no parecía viable. Galileo, por el contrario, consideraba que de hecho ésta era también una cuestión de "César o nada" porque el Papa así lo había planteado, que había que formularla con toda crudeza, y que había que atribuir al Papa toda la convicción, fortaleza y valentía que la radicalidad de su enfoque implicaba. No importaba si él consideraba improcedente el argumento, lo importante era que el Papa lo tomaba muy en serio, y así, muy en serio, había que plantearlo. El Papa tendría que decidir si le importaba más que los herejes pudieran reírse de su argumento o si de verdad estaba comprometido con éste y con su contundencia lógica, de modo que las hipotéticas risas no le importaran y las tratara como a cualquier impugnación de otras tesis o dogmas de la Iglesia.

42 Según cuenta Ranke: “Una vez se le hizo un reproche a base de las viejas constituciones pontificias, y su respuesta fue que las palabras de un Papa vivo tienen más valor que los estatutos de 


\section{La ratificación y radicalización del equívoco}

El hecho es que en 1624, apenas un año después de su elección, Urbano VIII, aún eufórico y prometiéndose un futuro brillante, todavía tenía intacta su gran confianza en sí mismo para hacer suyo el envite de Galileo, que en los años siguientes escribió su Diálogo sobre los dos máximos sistemas, anunciado en la Carta a Ingoli y con la misma perspectiva. En 1630, cuando Galileo fue a Roma a presentar su Diálogo a la censura, la situación política ya había frustrado las optimistas previsiones que Urbano VIII se había hecho en el inicio de su pontificado. Lejos de convertirse en árbitro de la política europea, como había soñado, sus alianzas con Richelieu, que a su vez había pactado con los protestantes, habían venido provocando una creciente oposición del Emperador y del rey de España, que había ido poniendo al Papa en una situación cada vez más difícil. No obstante, su postura en el tema del copernicanismo y Galileo no parecía haber variado. Más aún, el 16 de marzo de 1630 Galileo se entera a través de Cesi y Castelli de que

«El padre Campanella, hablando hace días con Nuestro Señor [Urbano VIII], le dijo que había tenido en sus manos a ciertos alemanes a punto de convertirlos a la fe católica, y que estaban bien dispuestos. Pero que al saber de la prohibición de Copérnico etc., habían quedado tan escandalizados que no había podido hacer más. Y Nuestro Señor les respondió las siguientes palabras precisas: Nunca fue nuestra intención. Y si hubiese dependido de nos, no se habria hecho aquel decreto» (Opere XIV, 88; cursiva en original).

Era un momento excelente para que el Papa recordara o sacara a la luz la parte más liberal y permisiva de su postura respecto a la teoría copernicana. Como es bien sabido, Urbano VIII impuso algunas condiciones para la publicación del Diálogo. El padre Niccolò Riccardi, encargado de la censura, las enunciaba explícitamente al inquisidor florentino Clemente Egidi:

"No obstante, le recuerdo que es voluntad de Nuestro Señor [Urbano VIII] que el título y tema no sea sobre el flujo y el reflujo, sino únicamente

cien papas muertos» Ranke 1993, 466. En la misma página, nota 10, Ranke cita un Informe de cuatro embajadores sobre Urbano VIII, fechado precisamente en 1624 , en el que se lee: «Ama las propias opiniones y se deja lisonjear por su genio, de lo que deriva una férrea tenacidad en sus propias ideas". 
de la consideración matemática de la posición copernicana en torno al movimiento de la Tierra, con el fin de probar que, dejada aparte la revelación de Dios y la doctrina sagrada, se podrían salvar las apariencias con esta posición, resolviendo todos los argumentos contrarios que se podrían aportar a partir de la experiencia y de la filosofía peripatética, pero de modo que nunca se conceda la verdad absoluta a esta opinión, sino solamente la hipotética y sin las Escrituras. Además debe mostrarse que esta obra se hace solamente para mostrar que se conocen todos los argumentos que por esta parte [la copernicana] se pueden aducir y que en Roma no se ha rechazado esta sentencia por ignorarlos, de conformidad con el principio y el final del libro que le enviaré desde aquí arreglados. Con esta precaución el libro no tendrá impedimento alguno aquí en Roma y V. P. M. R. podrá complacer al autor y servir a la Serenísima Alteza que muestra una gran prisa en esto. Me reitero su servidor y le ruego favorezca con sus peticiones.

Roma, el 24 de mayo de 1631»(Opere XIX, 327).

El «final del libro" alude al argumento de Urbano VIII que Galileo incluyó en las últimas páginas del Diálogo y tenía un objetivo muy claro, que Riccardi expone al inquisidor el 19 de julio de 1630:

"Al final se deberá hacer la peroración de las obras (sic) como continuación de este prefacio, añadiendo el Sr. Galileo las razones de la divina omnipotencia que le dio Nuestro Señor, las cuales deben apaciguar el intelecto, aun en el caso de que no se pudiese librar uno de los argumentos pitagóricos (Opere XIX, 330; cursiva mía) ${ }^{43}$.

El «principio del libro» de que habla Riccardi hace referencia al prefacio del Diálogo que efectivamente fue enviado "arreglado", es decir con el contenido deseado por el Papa, que Galileo tenía la obligación de incluir, y así se publicó. En él se exponen más ampliamente las exigencias impuestas para el contenido y publicación del libro:

${ }^{43}$ Me he ocupado de los numerosos aspectos y problemas relacionadas con esta cuestión en mi próximo libro Talento y poder. Historia de las relaciones entre Galileo y la Iglesia, pero para mi propósito concreto aquí no necesito detenerme en este tema, sino sólo mencionar este texto. 
"Con este fin he tomado en la argumentación el partido de la teoría copernicana, considerándola como pura hipótesis matemática, tratando por cualquier medio artificioso de presentarla como superior a la tesis de la quietud de la Tierra no absolutamente, sino según el modo en que se defiende de algunos que, peripatéticos de profesión, lo son sólo de nombre, conformándose, sin paseo, con adorar las sombras, filosofando no a partir de la propia capacidad de reflexión sino sólo con el recuerdo de cuatro principios mal entendidos.

Se tratarán tres temas principales. En primer lugar, intentaré demostrar que todas las experiencias factibles en la Tierra son medios insuficientes para deducir su movilidad y que pueden adecuarse indistintamente tanto a una Tierra móvil como a una Tierra en reposo; y espero que en este aspecto se pondrán de manifiesto muchas observaciones que en la antigüedad no se conocían. En segundo lugar, se examinarán los fenómenos celestes, reforzando la hipótesis copernicana como si tuviese que quedar totalmente victoriosa, ańadiendo nuevas especulaciones que serán útiles para la mayor facilidad de la teoría astronómica, pero no por necesidad de la naturaleza. En tercer lugar, propondré una fantasía ingeniosa. Es el caso que hace muchos años yo dije que, admitiendo el movimiento terrestre, se podría arrojar alguna luz sobre el oscuro problema del flujo del mar. Corriendo de boca en boca, esta afirmación mía encontró padres caritativos que la adoptaban como hija de su propio ingenio. Ahora, para que no pueda aparecer extranjero alguno que, haciéndose fuerte con nuestras armas, nos eche en cara poca perspicacia en un accidente tan importante, he decidido poner de manifiesto las probabilidades que lo harían persuasible, suponiendo que la Tierra se moviese. Espero que, a partir de estas consideraciones el mundo sabrá que si otras naciones han navegado más, nosotros no hemos reflexionado menos y que el insistir en afirmar el estatismo de la Tierra y tomar lo contrario sólo como capricho matemático, no nace de no tener conciencia de lo que otros hayan pensado, sino, aunque no fuese por otra cosa, de las razones que la piedad, la religión, el conocimiento de la divina omnipotencia y la conciencia de la debilidad del ingenio humano nos suministran» (Opere VII, 29-30; cursiva mía).

Como vemos, las condiciones que Urbano VIII decidió establecer personalmente para la publicación del Diálogo, por más específicas que parezcan, están muy lejos de resultar claras; más bien al contrario, eran muy equívocas. Se dice 
explícitamente que se permite a Galileo considerar la posición copernicana "como pura hipótesis matemática» y que "nunca se conceda la verdad absoluta». Hasta aquí, y tomadas aisladamente, podría pensarse que estas exigencias se corresponden con las establecidas y explicadas en 1620, considerando la obra copernicana como un mero recurso de cálculo y fuente de observaciones. Sin embargo, incluso si no la restringimos a su uso para el calendario, una teoría astronómica, en cuanto recurso calculístico es mejor que otra en la medida en que pueda proporcionar medios de cálculo más sencillos y cómodos o predicciones más precisas o ambas cosas. $Y$ eso no tiene ninguna relación con la verosimilitud o coherencia de sus características cosmológicas y físicas. Ahora bien, Urbano VIII permite explícitamente a Galileo abordar precisamente estas cuestiones, le permite "tomar partido" por el copernicanismo e intentar mostrar "por cualquier medio artificioso" que la teoría copernicana es «superior a la tesis de la quietud de la Tierra», precisamente en cuanto que es capaz de responder y superar todas las críticas que la cosmología y la física tradicionales - no la astronomía técnica- le hacían. Le autorizaba a examinar «los fenómenos celestes, reforzando la hipótesis copernicana como si tuviese que quedar totalmente victoriosa", y a demostrar la inanidad de "todos los argumentos contrarios que se podrían aportar a partir de la experiencia y de la filosofía peripatética» ${ }^{44}$. Además se permitía a Galileo hacer todo esto de modo convincente, hasta el punto de que «no se pueda librar uno de los argumentos pitagóricos [copernicanos]". Sólo había que añadir las cláusulas correspondientes en el sentido de que la teoría no era verdadera absolutamente. Es obvio que así se estaba fuera de los límites establecidos en 1620, de la hipótesis como mero recurso de cálculo, porque todo esto, explícitamente permitido por Urbano VII a Galileo y expuesto en el prefacio que se mandó "arreglado" desde Roma, equivalía a defender la teoría copernicana y a hacerlo como una hipótesis cosmológica corroborable, con la condición de que no se considerara corroborada ${ }^{45}$. Así pues, las directrices de Urbano VIII no dejaban de tener una considerable ambigüedad, lo cual refuerza la idea de que no había pensado la cuestión con el detalle que exigía. En todo caso, si hemos de suponerle una línea de congruencia, está claro que la permisividad del Papa respecto al Diálogo no es coherente con lo decretado en 1620 , sino con el plantea-

${ }^{44}$ Y efectivamente el Dialogo se presenta como una obra de cosmología física y en ningún momento se centra en los recursos calculísticos.

${ }^{45}$ Lo cual es sumamente importante si tenemos en cuenta que ambas cosas serían presentadas como cargos contra Galileo. 
miento de Galileo en la Carta Ingoli, con lo que quedaría patente que efectivamente el Papa lo había hecho suyo. También aquí, en el Diálogo, como en la Carta a Ingoli, era el argumento teológico de Urbano VIII, es decir, la jerarquía disciplinaria y moral, la superioridad de la teología sobre la ciencia, lo que neutralizaría los argumentos copernicanos, no el carácter meramente calculístico de la teoría heliocéntrica. De hecho, la explicación que da Urbano VIII de la función que tendrá su argumento al final del libro viene a confirmarlo. Es cierto que su formulación concreta resulta curiosa y un tanto enigmática. La afirmación de Urbano VIII de que su argumento "debe apaciguar" incluso a los más convencidos por los argumentos copernicanos oscila entre la proclama de su convicción de la ineludible fuerza lógica del argumento y la orden o compulsión moral y política; como si la fuerza de la racionalidad no pudiera prescindir del apoyo de la autoridad. Una ambigüedad que posiblemente más que delatar una inconfesada inseguridad, fruto de la conciencia de no dominar los entresijos teóricos de la cuestión, refleja simplemente la falta de reflexión seria. Sea como fuere, el equívoco se había ratificado. En consecuencia, ahora más que nunca, todo dependía de la firmeza del levantisco Urbano VIII para sostener aquella frágil trama de equívoco, de contundentes proclamas y silencios emboscados. Pero si en 1624 el recién elegido Urbano VIII hacía ostentación de su poder y capricho, en 1632 llevaba años batiéndose en retirada y tuvo que ceder abiertamente ante sus adversarios políticos internos y ante los defensores de la cultura tradicional. Y Galileo y su Diálogo se convirtieron en instrumento y víctima de unos y otros. Aquí no puedo ocuparme de esta cuestión con detalle y me limitaré apuntar muy sintéticamente lo siguiente.

La Carta a Ingoli no se había llegado a publicar ni se publicaría en vida de Galileo. Pero el Diálogo sí se publicó tras una larga censura, y la llegada de los primeros ejemplares a Roma coincidió con la mayor crisis política, interior y exterior, con la que se había enfrentado Urbano VIII. Ya no eran tiempos de euforia y ahora sí hubo quien se rasgó las vestiduras. Tras un periodo de búsqueda y elección de cargos contra un libro que había sido negociado con el Papa y publicado con el imprimátur de sus adoctrinados censores, se hicieron distinto tipo de acusaciones contra Galileo. Una de las importantes fue que Galileo no había presentado la teoría copernicana como una hipótesis puramente instrumental, que la defendía como probable y la creía verdadera. Naturalmente, dado lo que hemos expuesto hasta aquí, si bien era comprensible en boca de cualquier defensor de la tradición era difícilmente justificable en boca del Papa, que tenía una clara res- 
ponsabilidad en la cuestión. Y como bien sabemos, el fundamento de la acusación se basó en el oportuno descubrimiento del problemático documento de 26 de febrero de 1616, según el cual, tras la admonición de Bellarmino, el comisario del Santo Oficio, Michelangelo Segizzi había impuesto a Galileo el precepto de que no sostuviera, enseñara o defendiera ni de palabra ni por escrito la teoría copernicana (Opere XIX, 321-322). Remitiendo el delito de Galileo a la desobediencia de un decreto de 1616 se intentaba eludir el tema de la responsabilidad de Urbano VIII en la gestación, contenido y publicación del Diálogo. Por otra parte, está bien documentado que el tema que más despertó la ira del Papa fue la presentación del argumento de la omnipotencia divina que había obligado a Galileo a incluir al final del Diálogo. La única acusación explícita que se hizo en este sentido fue que Galileo había puesto el argumento en boca de Simplicio, "un necio" (Opere XIX, 326), pero está claro que tras este cargo había mucho más. Como hemos visto, la cuestión era mucho más importante y resulta comprensible que el Papa deseara silenciarla. En distintas partes del Diálogo (recuérdese lo dicho en la nota 22) Galileo había ridiculizado al jesuita $\mathrm{Ch}$. Scheiner, su enconado enemigo, por hacer un uso convencional de la temática de la omnipotencia divina. Nos consta que, a raíz de la publicación del Diálogo, los jesuitas instigaron contra Galileo. Y, más en concreto, sabemos que tanto el general de la orden jesuita, Muzio Vetelleschi, como Urbano VIII, habían alentado a Scheiner a "defender la astronomía común contra Galileo" (Opere XV, 184), lo que pone de manifiesto que hubo algún tipo de contacto entre Scheiner y Urbano VIII a propósito del Diálogo. Resulta muy difícil no pensar que Scheiner, indignado por la mordaz crítica que le había hecho Galileo por su uso tradicional de la temática de la omnipotencia divina, no pusiera al Papa en una muy difícil situación. Scheiner, como otros jesuitas, sí comprendía perfectamente los vericuetos de la cuestión y las catastróficas consecuencias prácticas que la presentación del tema por parte de Galileo tenía para la ciencia tradicional. Para Scheiner la postura de Galileo era sin duda una ridiculización de la temática de la omnipotencia divina, en especial en cuanto que burlaba su función de eficaz mecanismo de control. En 1624 Urbano VIII, envanecido por el nuevo poder asumido, era todo osadía y nadie pudo o se atrevió siquiera a intentar hacerle ver la complejidad del tema, a convencerle de los peligros que podía implicar la versión de Galileo. Ahora en cambio, en 1632, estaba gravemente debilitado y arrinconado por las incontenibles críticas de sus adversarios políticos internos, en especial los filo españoles encabezados por el cardenal Gaspar Borgia. Las acusaciones por su desprotección de la fe católica se aunaban con las denuncias que tantas veces 
le habían dirigido en los últimos años los jesuitas por favorecer indirectamente la ruina de la sabiduría tradicional, frivolizando con los innovadores. Ahora Scheiner sí pudo y supo presentarle la interpretación del argumento papal que había hecho Galileo como una ridiculización de la temática de la omnipotentia Dei absoluta y, por tanto, como una ridiculización del propio Urbano VIII. Y cuanto más claramente lo hiciera más sangrante había de resultar para el Papa, tan orgulloso de "su» argumento, la evidencia de su propia irreflexión, de su incompetencia. Por añadidura, era obvio que no se podía acusar abiertamente a Galileo, sin exponer a la luz la responsabilidad del Papa, que ahora se revelaba como irresponsabilidad. Efectivamente, este no fue nunca un cargo explícito contra Galileo, pero nos consta que la ira de Urbano VIII por esta cuestión sólo murió con él y, en todo caso, parece claro que fue la razón básica que le llevó a asumir el protagonismo en todo el proceso contra Galileo y fue determinante en su condena. La despiadada lógica de la situación llevó a Urbano VIII a tomar el atajo psicológico de la acusación de engaño. Galileo, tras lo dicho hasta aquí podemos entender por qué, jamás aceptó tal cargo. Durante el proceso de 1632-1633, como nueve años antes, sólo podía hacerse fuerte en el descampado de la coherencia, pero ahora, en el nuevo paisaje político, había quedado atrapado en las espesuras del renovado equívoco ${ }^{46}$.

\section{Bibliografía}

Besomi, Ottavio y Helbing, Mario, 1998, Dialogo sopra i due massimi sistemi del mondo tolemaico e copernicano, Edizione critica e commento a cura di Ottavio Besomi e Mario Helbing, Padova, Editrice Antenore, vol. I, testo; vol. II, commento.

Biagioli, Mario, 1993, Galileo Courtier, The Practice of Science in the Culture of Absolutism, The Chicago Univ. Press, Chicago.

BIANCHI, Luca, 1990, Il vescovo e i filosofi. La condanna parisina del 1277 e l'evoluzione dell' aristotelismo scolastico, Pierluigi Lubrina Editore, Bergamo.

- 1999, Censure et liberté intellectuelle à l'université de Paris (XIII-XIV siècles), Le Belles Lettres, París.

- 1999, "Galileo fra Aristotele, Clavio e Scheiner. La nuova edizione del Dialogo e il problema delle fonti galileiane», Rivista di storia della filosofia, 2, 1999, 189-227.

${ }^{46}$ Para el desarrollo de todos estos puntos, remito de nuevo a mi próximo libro, citado en la nota anterior. 
- 2000, "Interventi divini, miracoli e ipotesi sopranaturali nel Dialogo di Galileo», en Potentia Dei. L'omnipotenza nel pensiero dei secoli XVI e XVII, a cura di G. Ganziani, M. A. Granada, Y. Ch. Zarka, Angeli 2000, 239-251.

BuCCiantini, Massimo, 1995, Contro Galileo. Alle origini dell'affaire, Biblioteca di Nuncius, Studi e Testi, XIX, Leo S. Olchki, Firenze.

Campanella, Tomasso, (1616) 1994, $A$ defense of Galileo, translated with an introduction and notes by Richard J. Blackwell, University of Notre Dame Press, Notre Dame, London.

Coyne, G. V., S. J., Hoskin, M. A. and Pedersen, O., 1983, Gregorian reform of the Calendar. Proceedings of the Vatican Conference to commenmorate its 400th anniversary 1582-1982. Pontificia Academia Scientiarum, Specola Vaticana, Vaticano.

D'Addio, Mario, 1993, Il caso Galilei. Processo/Scienza/Verità, Edizioni Studium, Roma. Constituye una edición ampliada de dos artículos "Considerazioni sui processi a Galileon, publicados en la Rivista di Storia della Chiesa in Italia en 1983 y 1984.

Drake, Stillman, 1978, Galileo at Work. His Scientific Biography. The University of Chicago Press. Chicago and London.

Duhem, Pierre, (1908)1990, Sotzein ta Phainomena. Essai sur la notion de théorie physique de Platon à Galilée, Librairie Philosophique J. Vrin, París (orig. 1908).

FanTOLI, Annibale, 1997, Galileo, per il copernicanesimo e per la Chiesa, Studi Galileiani vol. 2, Seconda edizione riveduta e corretta, Specola Vaticana, Libreria Editrice Vaticana, Città del Vaticano.

FaVARO, Antonio, 1992, Scampoli galileiani. Ristampa anastatica dagli "Atri e Memorie" della Accademia Patavina di Science, Lettere ed Arti, A cura di Lucia Rossetti e Maria Laura Soppelsa, Edizioni Lint, Trieste. 2 vols.

FUNKENSTEIN, Amos, 1986, Theology and the Scientific Imagination from the Middle Ages to the Seventeenth Century, Princeton University Press, Princeton, New Jersey.

Galileo Galilei, 1968, Le Opere di Galileo Galilei, Edizione Nazionale, A cura di A. Favaro, 20 vols. Firenze, G. Barbèra (1. ${ }^{\text {a }}$ ed. 1890-1909).

Grant, Edward, 1996, The Foundations of Modern Science in the Middle Ages. Their Religious, Institutional and Intellectual Contents, Cambridge Univ. Press, Cambridge.

Grant, Edward, (Ed.), 1974, A Source Book in Medieval Science, Harvard University Press, Cambridge, Mass.

LERNER, Michel-Pierre, 1995, "L'entrée de Tycho Brahe chez les jésuites ou le chant du cygne de Clavius", en L. Ciard (Ed.), Les jesuites à la Renaissance, PUF, París, 1995 
MaYaud, Pierre-Noël, 1997, La condamnation des livres coperniciens et sa révocation à la lumière de documents inédits des Congregations de l'Index et de l'Inquisition, Editrice Pontificia Università Gregoriana, Roma.

Tagliabue, G., 1963, I processi di Galileo e l'epistemologia, Edizioni di Comunità, Milano.

PASTOR, L., 1932-1968, Historia de los Papas desde fines de la Edad Media, Versión española de la cuarta edición alemana por el P. José Monserrat $S$. J., Barcelona, Gustavo Gili, 39 vols. (Las fechas en las referencias del texto corresponden a la de cada volumen citado).

RaNKe, Leopold von, 1993, Historia de los papas, F.C.E., México (orig. 1834-1836).

RoSEn, Edward, 1958, "Galileo's Misstatements about Copernicus", en Isis 49, 1958, 310-330.

Santillana, Giorgio de, 1960, Processo a Galileo. Studio Storico-Critico, Traduzione di Giacinto Cardona e Anna Abetti riveduta sulla edizione originale inglese con nuova prefazione dell'autore. Arnoldo Mondadori Editore, Roma. 